\title{
Absorption Coefficient of Molten Aluminum Oxide in Semitransparent Spectral Range
}

\author{
Vladimir K. Bityukov ${ }^{1}$ \& Vadim A. Petrov ${ }^{1}$ \\ ${ }^{1}$ Moscow State Technical University of Radio Engineering, Electronics and Automation, 78, Prospekt \\ Vernadskogo, Moscow, Russia \\ Correspondence: Vadim Petrov, Moscow State Technical University of Radio Engineering, Electronics, and \\ Automation, 78, Prospekt Vernadskogo, Moscow 119454, Russia. Tel: 7-495-434-9454. E-mail: \\ vapetrov@mirea.ru
}

Received: October 7, 2012 Accepted: October 26, 2012 Online Published: January 9, 2013

doi:10.5539/apr.v5n1p51 URL: http://dx.doi.org/10.5539/apr.v5n1p51

\begin{abstract}
A critical compilation and analysis of all the available experimental data and approximation formulas for the wavelength and temperature dependences of the absorption coefficient of molten aluminum oxide in semitransparent region are presented. The main factors and the influence of physicochemical processes on the value of the absorption coefficient are considered. Special attention is focused on possible reasons for large values of absorption of the alumina melt as compared to the crystal near melting temperature. It is shown that the available data can be divided into two groups, according to the level of absorption. The first group includes the results of the research of optical properties of solid propellant combustion products, and the second group-the results of the research of single crystal melts and some other high-purity molten aluminum oxides. Along with the detailed analysis of the absorption coefficient, also a brief analysis of available data on the refractive index has been done.
\end{abstract}

Keywords: molten aluminum oxide, absorption coefficient, absorption index, refractive index, semitransparent wavelength range, radiation heat transfer

\section{Introduction}

Investigation of temperature and spectral dependences of the absorption coefficient $\alpha$ of molten aluminum oxide $\mathrm{Al}_{2} \mathrm{O}_{3}$ have both a scientific and practical importance. For science, it can be of interest because during melting this oxide not only dramatically changes the value of the absorption coefficient but also other thermophysical properties. Electrical conductivity, for example, increases by three orders of values, while the density decreases more than $20 \%$. It may be an indirect evidence of changes in arrangement of atoms in the melt. In the course of solidification of small-size droplets significant supercooling may take place, reaching hundreds of Kelvin, as well as formation of metastable crystal phases. The practical importance is connected with the application in various fields of electronics, semiconductor and infrared techniques of single crystals of corundum being grown from melts, as well as with the application of aluminized solid rocket fuel, when as a result of combustion, droplets of molten aluminum oxide are formed.

It is also important that aluminum oxide is probably the only one from refractory oxides for which melt a big amount of experimental data on the dependence of $\alpha$ on temperature $T$ and wavelength $\lambda$ are available today. However, the data have been obtained on different samples using different methods, and in various environment conditions. The differences in the data are enormous, sometimes extending to two or three orders of magnitude. The reasons for these big differences are not quite evident, what is evident is the fact that they exceed significantly the errors of individual experiments. It is, therefore, expedient to make a critical analysis of the available experimental data for the absorption coefficient of molten aluminum oxide, taking into account physicochemical processes which affect its value.

Aluminum oxide, like zirconium oxide, oxides of yttrium, magnesium and some other elements, is a semitransparent substance both in the solid and molten state. It is well known (Mitra, 1985) that these substances at room temperature absorb radiation in semitransparent wavelength range due to phonon-assisted electronic transitions in the long-wavelength tail of the fundamental electronic absorption edge (Urbach tail), presence of defects and impurities, and lattice vibrations. The first of them determines the short-wavelength edge of 
semitransparency, the second is most important at the low absorption plateau, and the third determines the long-wavelength edge of semitransparency. The analysis of temperature and wavelength dependence of the absorption coefficient requires consideration of the mentioned three factors (Thomas, 1991). Thomas (1991) developed a model to account for multiphonon absorption at the long-wavelength edge of semitransparency as a function of temperature. Lynch (1985) proposed a formula, which represented absorption in the Urbach tail. However, the theoretical models and formulas cannot give satisfactory results for the absorption coefficient of real substances and materials. Reliable data can be obtained only experimentally.

The experimental values of optical properties of aluminum oxide at room temperature, obtained from various references, were presented by Gervais (1991) and Tropf and Thomas (1998). According to experimental results of French (1990), single crystal of $\mathrm{Al}_{2} \mathrm{O}_{3}$ at room temperature is highly insulating substance characterized by mixed ionic and covalent bonding, a large band gap energy (forbidden zone), which is equal to $8.8 \mathrm{eV}$, and a limited range of atomic nonstoichiometry and concomitant low concentrations of both ionic defects and electronic carriers. The absorption coefficient equals to approximately $10 \mathrm{~cm}^{-1}$ at wavelength of $0.15 \mu \mathrm{m}$ (Innocenzi, Swimm, Bass, French, Villaverde, \& Kokta, 1990). The electronic structure of $\mathrm{Al}_{2} \mathrm{O}_{3}$ at high temperature is controlled by the effects of thermal lattice expansion and the electron-phonon interaction. These cause shifts and broaden the valence and conduction bands, leading to an increase in electronic carrier concentration and absorption coefficient. The band gap energy decreases from $8.8 \mathrm{eV}$ at $300 \mathrm{~K}$ to $7.2 \mathrm{eV}$ at $1763 \mathrm{~K}$ (French, 1990). In visible spectral range the absorption coefficient $\alpha$ increases by dozens of times, however, even so, its value near the melting temperature does not exceed $0.4 \mathrm{~cm}^{-1}$, and crystal of $\mathrm{Al}_{2} \mathrm{O}_{3}$ remains in semitransparent state (Lingart, Petrov, \& Tikhonova, 1982). In solid state, the spectral region of conventional semitransparency, provided the region's boundaries are a wavelengths range, where $\alpha<10 \mathrm{~cm}^{-1}$, at room temperature extends approximately from $0.15 \mu \mathrm{m}$ to $6.2 \mu \mathrm{m}$, and along with the increase of temperature up to $2300 \mathrm{~K}$, the long wavelength boundary of the region shifts towards shorter wavelengths up to about $4.8 \mu \mathrm{m}$, and the short wavelength boundary - to the visible region. In the region of the least absorption from 2.2 to $3.2 \mu \mathrm{m}, \alpha$ increases from 0.0014 to $0.12 \mathrm{~cm}^{-1}$.

The spectral and temperature dependences of the absorption coefficient of single crystal aluminum oxide (leucosapphire), especially in semitransparent range, have been rather well investigated. The discrepancies in the research results of different authors are relatively small for the wavelength range of 3.5-6 $\mu \mathrm{m}$. The data for the range from 1 to $3 \mu \mathrm{m}$ at high temperatures are much less. The analysis of the experimental data known before 1982 and the recommended values of $\alpha$ in the wavelength range from $0.5 \mu \mathrm{m}$ to $7 \mu \mathrm{m}$ and at temperatures ranging from 300 to $2300 \mathrm{~K}$, that is, almost to the melting temperature, is presented by Lingart et al. (1982). Since then actually no new data have been published for the absorption coefficient of $\mathrm{Al}_{2} \mathrm{O}_{3}$ crystal at high temperatures and within the range of 1-3 $\mu \mathrm{m}$. Only small-scale graphs have additionally appeared concerning the dependence of emissivity $\varepsilon$ on the wavelength (Rosenbaum, De Sousa Meneses, Auger, Chermanne, \& Echegut, 1999; Brun, De Sousa Meneses, \& Echegut, 2003), although the question of changing of thermal radiation characteristics in the pre-melting temperatures is discussed (Rosenbaum et al., 1999; Brun et al., 2003; Petrov \& Vorobyev, 2005; Vorob'ev, Petrov, Titov, \& Chernyshev, 2007). Only the scale of graphs of $\varepsilon(\lambda)$ dependence in reference (Sarou-Kanian, Rifflet, \& Millot, 2005) allows to estimate the value of the absorption coefficient of the crystal on the basis of the provided data for $\varepsilon$.

The abrupt increase of the absorption coefficient during transition from the solid to molten state was observed for the first time apparently by Gryvnak and Burch (1965). However, direct measurements of the absorption coefficient $\alpha$ were not made in that work, but a significant difference was revealed in brightness temperatures of solid and liquid phases near the edge of the pool with the melt produced by melting of the central part of a leucosapphire single crystal sample. The results of that paper show that at a wavelength of $0.65 \mu \mathrm{m}$, after melting in a hydrogen-oxygen flame, $\alpha$ increases 30-40 times and maybe even more. At a wavelength of $2.2 \mu \mathrm{m}$, after melting the brightness increases 15-20 times. After solidification no irreversible change of $\alpha$ compared to the original crystal was noted in that research.

The question of abrupt increase of the absorption coefficient after melting of $\mathrm{Al}_{2} \mathrm{O}_{3}$ is considered in detail by Petrov (2009), however, the problem continues to be relevant. It needs to note that the structure of an artificial crystal of pure $\mathrm{Al}_{2} \mathrm{O}_{3}$ (leucosapphire) is a thermodynamically stable $\alpha$-phase (corundum), in which the oxygen sublattice has a hexagonal close-packed structure. However, aluminum oxide has a number of metastable phases, which are obtained, in particular, by way of very rapid cooling of micron-size molten droplets. One of the phases, most frequently revealed after the rapid crystallization is a non-equilibrium $\gamma$-phase, in which the oxygen sublattice has a cubic face-centered structure of spinel (Levy, Jayaram, Valencia, \& Mehrabian, 1988). This may testify indirectly to the fact that during the process of melting of $\mathrm{Al}_{2} \mathrm{O}_{3}$ and at subsequent heating after the 
melting, the atom arrangement in the local atomic order of aluminum oxide may differ from the atom arrangement in corundum, which may be the reason for non-monotonic variation of the absorption coefficient. Yet, there is so much unclear in the formation of different crystalline structures during solidification of small-size droplets. In the most detailed study (Levy et al., 1988), the experimentally obtained results show that solidified droplets of diameters ranging from $0.01 \mu \mathrm{m}$ to $0.1 \mu \mathrm{m}$ are mostly x-ray amorphous, droplets of diameters from $0.1 \mu \mathrm{m}$ to $10 \mu \mathrm{m}$ are of $\gamma$-phase, and droplets of diameters exceeding $20 \mu \mathrm{m}$ are of stable $\alpha$-phase. The latter, according to the authors' opinion of reference (Levy et al., 1988), does not mean that the $\alpha$-phase is formed immediately at the crystallization of the melt, they believe that most probable the initial crystallization of $\mathrm{Al}_{2} \mathrm{O}_{3}$ melt is in $\gamma$-phase which later after recalescence $\mathrm{Al}_{2} \mathrm{O}_{3}$ transforms into the $\alpha$-phase.

It should be noted, however, that despite obvious evidences of big differences in the values of the absorption coefficient of the melt and the crystal near the melting point, indicative of the abrupt increase of the absorption coefficient at melting, not all researchers, involved in studying of the absorption coefficient of the molten alumina, agree with this view.

The main objective of this article is to make a critical compilation and analysis of all the available experimental data and approximation formulas for the wavelength and temperature dependences of the absorption coefficient of molten aluminum oxide in semitransparent region and, where possible, to consider the reasons for large discrepancies in data in various works. The associated tasks are to consider the influence of various factors and, first of all, the influence of the environment and impurities on the value of the absorption coefficient of molten alumina, as well as to examine the novel achievements in the study of atomic structure so as to find a possible reason for large values of absorption of the alumina melt as compared to the crystals analyzed.

\section{Analytical Dependences of the Absorption Coefficient (Absorption Index) on the Wavelength and Temperature}

For more than 40 years researches have been investigating the absorption coefficient $\alpha$ or absorption index $\kappa$ $(\kappa=\alpha \lambda / 4 \pi)$ of molten $\mathrm{Al}_{2} \mathrm{O}_{3}$ and there have been made several attempts to obtain the dependence of the absorption coefficient on the wavelength and temperature in analytical expressions. In fact, the use of analytical approximation of dependencies $\kappa=f(\lambda, T)$, significantly simplifies calculating of radiative, radiative-conductive and radiative-convective heat transfer in molten $\mathrm{Al}_{2} \mathrm{O}_{3}$. Among the first attempts in this direction was the work the results of which are presented in reference (Parry \& Brewster, 1991). In this work, in addition to finding of analytical dependence $\kappa=f(\lambda, T)$, also experimental investigation is carried out focusing on particles produced as a result of burning of aluminized solid propellants in conditions similar to the conditions of burning in a real rocket motor. The burning in the experiment was in nitrogen. Measurements are made of bidirectional transmittance (forward scattering of light at an angle of $11^{\circ}$ relative to the normal to the flame) and bidirectional reflectivity (back scattering of light at an angle of $17^{\circ}$ relative to the normal). The relative method is used for measurement. As the reference standards the special cells that geometrically correspond to the flame under study, with a suspension from latex spheres of diameters of $107 \mathrm{~nm}$ and $200 \mathrm{~nm}$, were used. The helium-neon and YAG lasers (wavelengths of $632.8 \mathrm{~nm}$ and $1.06 \mu \mathrm{m}$ respectively) are used as sources of probing radiation. The calculations are made based on the Mie theory. The values of $n$ and $\kappa$ and also parameters characterizing particle size distribution were obtained. The calculation results of transmittance and reflectivity are compared with obtained experimental data. In the complicated and effort-consuming experiment only two points are obtained for absorption and refractive indices and only at one temperature, of $2680 \mathrm{~K}$. As a result, $\kappa=0.006 \pm 0.004$ for both wavelengths, and $n_{1}=1.65$ and $n_{2}=1.64$, respectively. On the basis of these data, and using data of other researchers (the results of Mularz \& Yuen (1972); information provided to the authors of reference (Parry \& Brewster, 1991) by B. Reed in private, which presents the expression describing the dependency of $\kappa$ particles, collected from a rocket plume and heated in a shock tube, on temperature and wavelength in the range from $1.7 \mu \mathrm{m}$ to $4.5 \mu \mathrm{m}$, and also $\mathrm{G}$. Gal and $\mathrm{H}$. Kirch's data for temperature of $3000 \mathrm{~K}$ in the range from $0.5 \mu \mathrm{m}$ to $5 \mu \mathrm{m}$, which Parry and Brewster (1991) consider as a simple extrapolation from a solid phase), a dispersion analysis is made using the classical dispersion theory. Based on the model of two oscillators with characteristical wavelengths of $0.1107 \mu \mathrm{m}$ and $17.57 \mu \mathrm{m}$, taken on the basis of the results of earlier published works on dispersion analysis of $\mathrm{Al}_{2} \mathrm{O}_{3}$ single crystal at room temperature (Gervais, 1991; Tropf \& Thomas, 1998), and on traditional fitting of approximation dependences using the least squares method, there are found expressions for a number of empirical coefficients, which characterize the dispersion parameters for a real and imaginary part of dielectric permittivity. In reference (Parry \& Brewster, 1991) the results of calculation of $\kappa$ and $n$ of molten $\mathrm{Al}_{2} \mathrm{O}_{3}$ in the wavelengths ranging from $0.5 \mu \mathrm{m}$ to $5 \mu \mathrm{m}$, at temperatures of $2320,2500,2680,2800$ and $3000 \mathrm{~K}$ are presented. Figure 1 shows the calculation results for the dependence of the absorption coefficient $\alpha$ on the wavelength at these temperatures, made on the basis of data of reference (Parry \& Brewster, 1991). 


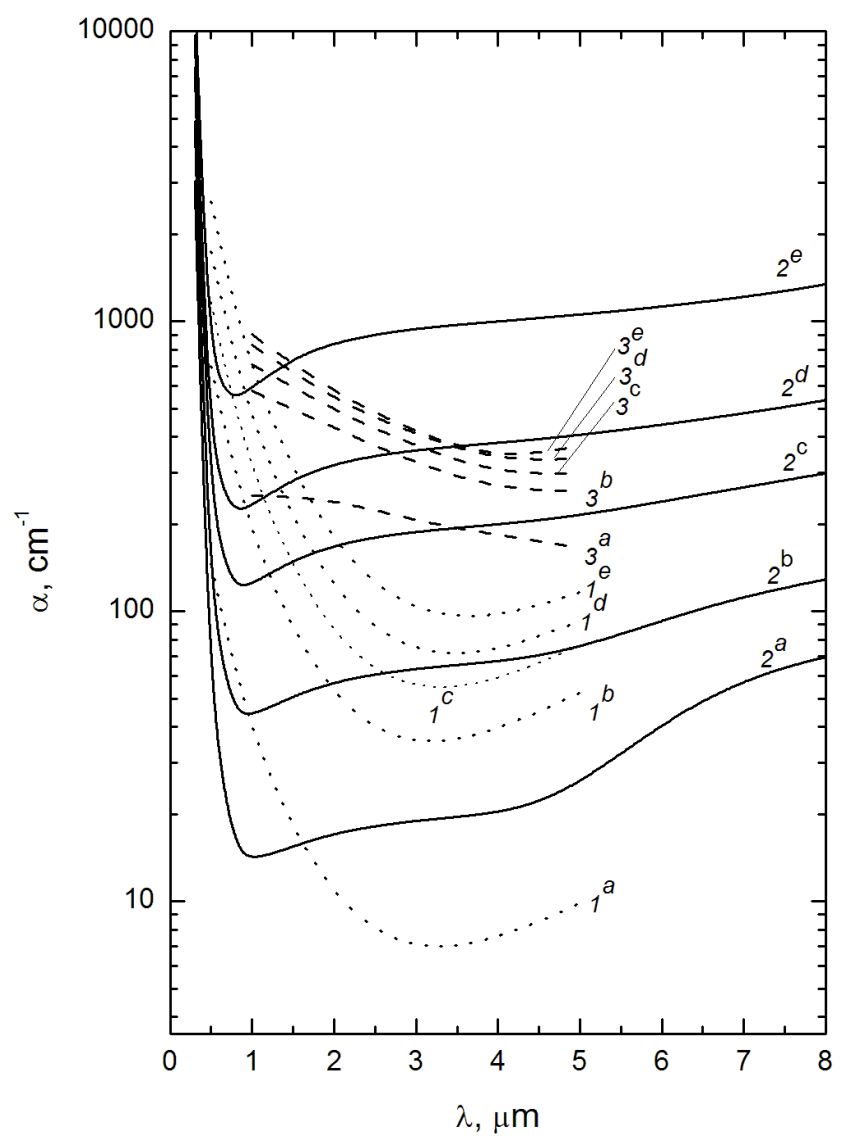

Figure 1. Analytical wavelength and temperature dependences of the absorption coefficient of molten aluminum oxide

1 - Parry \& Brewster, 1991: a - $2320 \mathrm{~K}, \mathrm{~b}-2500 \mathrm{~K}, \mathrm{c}-2680 \mathrm{~K}, \mathrm{~d}-2800 \mathrm{~K}, \mathrm{e}-3000 \mathrm{~K} ; 2$ - Plastinin et al., 2000: a $-2327 \mathrm{~K}, \mathrm{~b}-2500 \mathrm{~K}, \mathrm{c}-2680 \mathrm{~K}, \mathrm{~d}-2800 \mathrm{~K}, \mathrm{e}-3000 \mathrm{~K} ; 3$ - Kuz'min, 2004: a - $2327 \mathrm{~K}, \mathrm{~b}-2500 \mathrm{~K}$, $\mathrm{c}-2680 \mathrm{~K}, \mathrm{~d}-2800 \mathrm{~K}, \mathrm{e}-3000 \mathrm{~K}$.

In reference (Anfimov, Karabadjak, Khmelinin, Plastinin, \& Rodionov, 1993), the authors, based on the results of their own measurements in the range from $0.2 \mu \mathrm{m}$ to $7 \mu \mathrm{m}$, present empirical expressions for four items of the absorption index of molten $\mathrm{Al}_{2} \mathrm{O}_{3}: \kappa=\kappa_{0}+\kappa_{1}+\kappa_{2}+\kappa_{3}$. The first item is determined by the contribution of atoms vibrations, the second - by the contribution of free electrons, the third - by the fundamental absorption band of bound electrons (absorption in the UV region due to interband transition of electrons), and the fourth - by the Urbach long-wavelength edge of absorption of this band. No details of obtaining of these empirical expressions are given, and the initial data for the emissivity of droplets from chemically pure $\mathrm{Al}_{2} \mathrm{O}_{3}$ that are on the tungsten disc, are not presented either. The approach suggested by Anfimov et al. (1993) was further developed by Plastinin et al. (2000) in the paper published later. The coefficients are specified for the items of the absorption index of molten $\mathrm{Al}_{2} \mathrm{O}_{3}$ and argumentation is given for selection of empirical parameters. It turns out that the absorption due to contribution of the atomic vibrations in the melt is neglected in reference (Plastinin et al., 2000), yet the short-range order of arrangement of atoms in the melt is retained, and it is necessary to take into account absorption contribution on atoms vibrations in the $\mathrm{Al}-\mathrm{O}$ bond. The temperature and wavelength ranges, in which empirical expressions are needed to be used to account different contributions, are, unfortunately, not given in reference (Plastinin et al., 2000). The data for obtained dependence of spectral emissivity on the wavelength are given in the range from $1.2 \mu \mathrm{m}$ to $8.5 \mu \mathrm{m}$ only at temperatures close to the temperature of solidification. Our calculations of contribution of $\kappa_{2}$, using the empirical expression and the parameters given by Plastinin et al. (2000), show that this component, after falling with the increase of wavelength in the ultraviolet region, begins to increase abruptly in the visible region, and its value amounts to several tens and even hundreds in the infrared spectrum zone. Therefore we ignore it in our calculation of the total value of the absorption index, 
performed for the range from $0.2 \mu \mathrm{m}$ to $8 \mu \mathrm{m}$. The description given by Plastinin et al. (2000) seems not quite physical of the absorption at the Urbach edge, which begins to rise at wavelengths of more than $2.5 \mu \mathrm{m}$, but we have not introduced any changes to the empirical expression for $\kappa_{3}$, since the absorption contribution in the IR region is small enough. We thought it necessary to account in the total absorption the contribution of absorption on atomic vibrations $\kappa_{0}$. As the parameters, characterizing the absorption, we took the parameters used in reference (Plastinin et al., 2000) for crystalline $\gamma$-phase and performed calculation of the total absorption index as $\kappa=\kappa_{0}+\kappa_{1}+\kappa_{3}$. The values of the absorption coefficient $\alpha$, calculated on the basis of thus obtained values of the absorption index $\kappa$, are shown in Figure 1. As it should be, the ratio of contributions of various components largely depends on the wavelength. At a wavelength of $0.5 \mu \mathrm{m}$, the absorption contribution of the atomic vibrations, $\kappa_{0}$, is negligibly small, the contribution of free electrons is $\kappa_{1}=5.68 \cdot 10^{-5}$, the contribution due to absorption at the Urbach edge is $\kappa_{3}=5.19 \cdot 10^{-4}$. At the wavelength of $3 \mu \mathrm{m}$ we obtained that $\kappa_{0}=3.9 \cdot 10^{-9}$, $\kappa_{1}=1.48 \cdot 10^{-3}, \kappa_{3}=3.34 \cdot 10^{-5}$. At the wavelength of $8 \mu \mathrm{m}, \kappa_{0}=2.65 \cdot 10^{-3}, \kappa_{1}=5.51 \cdot 10^{-3}, \kappa_{3}=5 \cdot 10^{-5}$.

The third among the researches, where an attempt was made to present approximation analytical dependences of the absorption index for the molten aluminum oxide, is reference (Kuz'min, 2004). In this work, data on the absorption index were obtained on the basis of measurements carried out during the operation of subscale rocket motor using solid propellant fuel. The author of (Kuz'min, 2004 ) notes that the optical properties of aluminum oxide droplets in the motor plume, due to the effect of various impurities, differ significantly from the optical properties of pure aluminum oxide. The experimentally obtained data on the dependence $\kappa(\lambda$, T) were approximated as polynomials and power series. The temperature dependence for wavelengths $1 \mu \mathrm{m}, 2 \mu \mathrm{m}, 3 \mu \mathrm{m}$, $4 \mu \mathrm{m}$ and $5 \mu \mathrm{m}$ was described by a polynomial of the form $\kappa_{\lambda \mathrm{i}}(T)=A_{0}+A_{1} \cdot T+A_{2} \cdot T^{2}+A_{3} \cdot T^{3}$, and the dependence on wavelength for the three temperatures of 2500,3000 and $3300 \mathrm{~K}$ was described by the formula $\kappa_{\mathrm{Ti}}(\lambda)=\sum_{\mathrm{i}=0}^{8} \mathrm{~A}_{\mathrm{i}} \lambda^{\mathrm{i}}$. The latter expression is obtained for the wavelengths ranging from $0.5 \mu \mathrm{m}$ to $5 \mu \mathrm{m}$. To our regret, our calculations were made on the basis of $A_{i}$ values given by Kuz'min (2004) in Table 2.8 on page 60 of that reference, gave very queer values of $\kappa$, which did not agree with the calculations made by the polynomial function. At a temperature of $2500 \mathrm{~K}$, for example, the value of $\kappa$ varied from 0.47 to 0.7 , which is the evidence of errors in the values of the coefficients given in Table 2.8 of reference (Kuz'min, 2004). So, Figure 1 shows the data on $\alpha$, obtained on the basis of our calculations of $\kappa$ using the polynomial function of reference (Kuz'min, 2004) for five wavelengths of $1 \mu \mathrm{m}, 2 \mu \mathrm{m}, 3 \mu \mathrm{m}, 4 \mu \mathrm{m}$ and $5 \mu \mathrm{m}$.

In Figure 1 it is clearly seen that there are big qualitative and quantitative differences in the three published analytical descriptions of temperature and spectral dependences of the absorption coefficient $\alpha$ of molten aluminum oxide. And even the calculation results made on the basis of the expressions received in the two works (Parry \& Brewster, 1991) and (Kuz'min, 2004), where for the approximation were used the results for molten droplets of solid propellant combustion products, there was a divergence of more than one order. This suggests for a joint analysis of all available data on the absorption coefficient of molten $\mathrm{Al}_{2} \mathrm{O}_{3}$, regardless of whether analytical description of the obtained dependences is available or not.

\section{Absorption Coefficient (Absorption Index) of Molten Aluminum Oxide Particles}

There have been published rather many works with experimental data on absorption coefficient $\alpha$ (absorption index $\kappa$ ) of molten aluminum oxide. However, because of the dependence of these parameters both on temperature and wavelength it seems hard to compare the results of different investigators, as in different studies there are different wavelength or temperature ranges. Anyway, we tried to collect all the direct measurement results, which we could find, and show these data in Figure 2 as the dependence of the absorption coefficient on the wavelength. The considered above analytical expressions are not shown in this Figure. Most of the results from various papers are presented in the form of curves, but some are shown as separate points at discrete values of wavelengths, the way they are given in the original publications.

Now let us consider the published results in chronological order.

The first work, where the investigation was made of the emissivity of flow of combustion products with molten aluminum oxide particles, aimed at determining of the absorption coefficient of the melt, seems to be reference (Carlson, 1965). Polydisperse particles of $\mathrm{Al}_{2} \mathrm{O}_{3}$ (diameter from 1 to $10 \mu \mathrm{m}$ ) were heated in the small-size rocket motor, working as a hydrogen-oxygen torch at atmospheric pressure (the nozzle was removed). It was discovered that the emissivity of the flow depended on the distribution of particles according to their sizes, and in the wavelength region, where the flame did not affect radiation, it depended significantly on temperature in the range from the melting temperature (taken as $2320 \mathrm{~K}$ ) to $3000 \mathrm{~K}$. However, in that work the value of the absorption index was not calculated. Such calculation was made later by Adams (1967), and the obtained data on absorption 
index $\kappa$ were averaged in the wavelength range of 1.3-1.7 $\mu \mathrm{m}$. The results of that calculation showed that the value of $\kappa$, with temperatures varying from the melting temperature up to $3000 \mathrm{~K}$, increased approximately 18 times. If we take these data for $\kappa$ and calculate the absorption coefficient $\alpha$, it is seen that in accordance with the results of reference (Adams, 1967), for a wavelength of $1.3 \mu \mathrm{m}$ in this temperature range, $\alpha$ varies from $17.5 \mathrm{~cm}^{-1}$ to $315 \mathrm{~cm}^{-1}$, while for a wavelength of $1.7 \mu \mathrm{m}$, it varies from $13.4 \mathrm{~cm}^{-1}$ to $240 \mathrm{~cm}^{-1}$. The related data for $\alpha$ are shown in Figure 2 as results obtained by Carlson (1965).

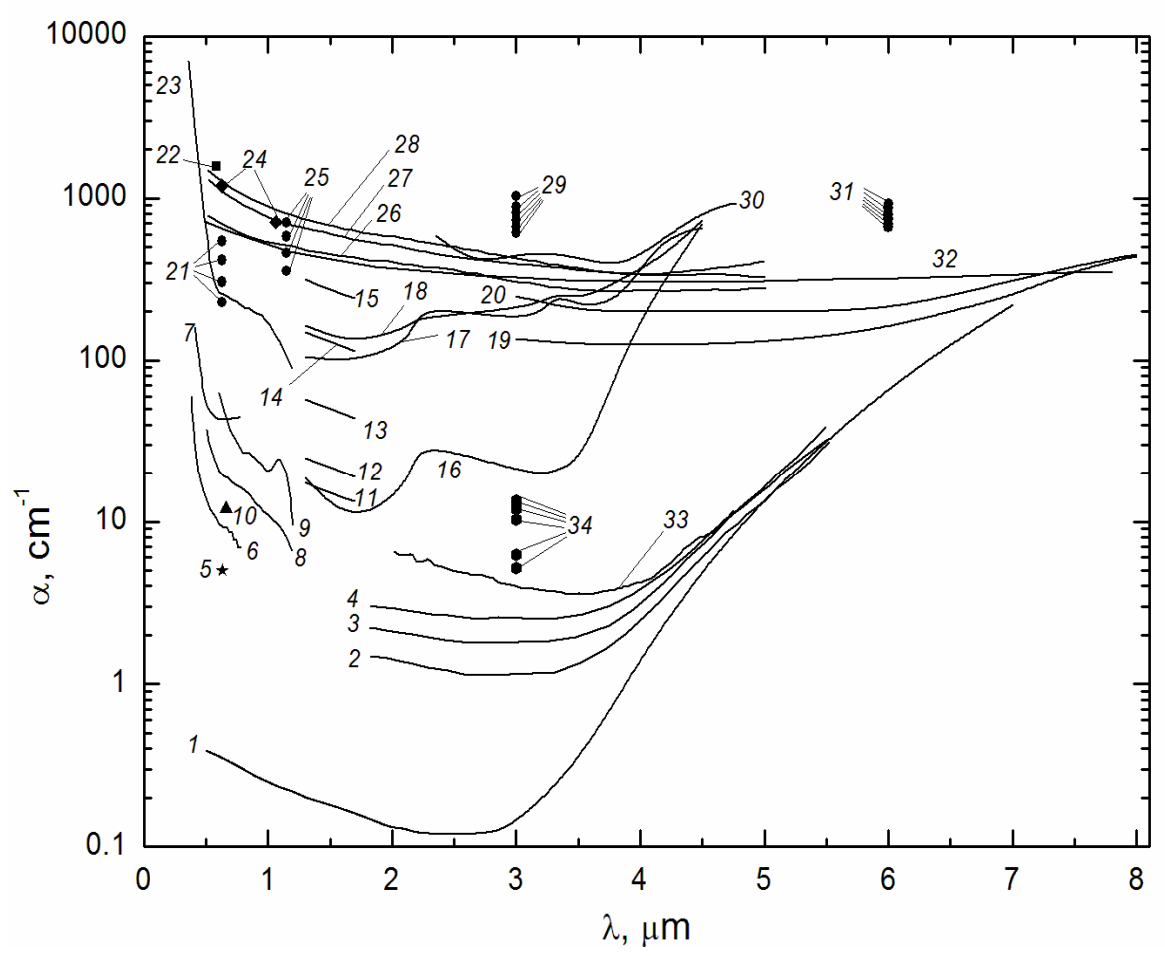

Figure 2. Experimental data from different papers

1 - recommended data (Lingart et al., 1982) for solid single crystal at $2300 \mathrm{~K} ; 2,3,4$ - (Brun et al., 2003) for temperature of $2320 \mathrm{~K}, 2340 \mathrm{~K}$ and $2360 \mathrm{~K}$ accordingly; 5 - (Nason, Yen, \& Tiller, 1990) for $2473 \mathrm{~K} ; 6,7$ (Weber, Krishnan, Anderson, \& Nordine, 1995) for argon and oxygen accordingly; 8, 9 - (Rubtsov, Emelyanov, \& Ponomarev, 1984) for $2330 \mathrm{~K}$ and $2440 \mathrm{~K}$ accordingly; 10 - (Abrevaya \& Nordine, 1988); 11, 12, 13, 14, 15 (Carlson, 1965) for $2320 \mathrm{~K}, 2400 \mathrm{~K}, 2600 \mathrm{~K}, 2800 \mathrm{~K}$, and $3000 \mathrm{~K}$ accordingly; 16, 17, 18 - (Konopka, Reed, \& Calia, 1984) for particles of rocket motor 1 at temperatures of $2375 \mathrm{~K}, 2959 \mathrm{~K}$ and $2736 \mathrm{~K} ; 19,20$ - (Vorobyev, Petrov, Titov, \& Chernyshev 1999) for $2500 \mathrm{~K}$ and $2700 \mathrm{~K} ; 21$ - (Shigapov, 1998) for $2400 \mathrm{~K}, 2500 \mathrm{~K}, 2600 \mathrm{~K}$, and $2700 \mathrm{~K} ; 22$ - (Adams, 1967) for 2500 - $2900 \mathrm{~K} ; 23$ - (Mularz \& Yuen, 1972) for $2550 \mathrm{~K} ; 24$ - (Parry \& Brewster, 1991) for $2680 \mathrm{~K} ; 25$ - (Shigapov, 1998) for $2400 \mathrm{~K}, 2500 \mathrm{~K}, 2600 \mathrm{~K}$, and $2700 \mathrm{~K} ; 26$, 27, 28 (Kuz'min, 2004) for $2700 \mathrm{~K}, 3000 \mathrm{~K}, 3300 \mathrm{~K} ; 29$ - (Shigapov, 1998) for $2400 \mathrm{~K}, 2500 \mathrm{~K}, 2600 \mathrm{~K}, 2700 \mathrm{~K}, 2800 \mathrm{~K}$ and $2900 \mathrm{~K} ; 30$ - (Konopka et al., 1984) for particles of $\mathrm{Al}_{2} \mathrm{O}_{3}$ commercial grade at $2700 \mathrm{~K} ; 31$ - (Shigapov, 1998 ) for $2400 \mathrm{~K}, 2500 \mathrm{~K}, 2600 \mathrm{~K}, 2700 \mathrm{~K}, 2800 \mathrm{~K}$ and $2900 \mathrm{~K} ; 32$ - (Bakhir, Levashenko, \& Tamanovich, 1977) for $2950 \mathrm{~K} ; 33$ - (Sarou-Kanian et al., 2005) for $2300 \mathrm{~K}$; 34 - (Sarou-Kanian et al., 2005) for $2327 \mathrm{~K}$, $2400 \mathrm{~K}, 2500 \mathrm{~K}, 2600 \mathrm{~K}, 2700 \mathrm{~K}, 2800 \mathrm{~K}$.

In reference (Adams, 1967), the author also presents his own research results of the absorption index for a wavelength of $0.588 \mu \mathrm{m}$ in the temperature range from 2460 to $2900 \mathrm{~K}$. The experiments were carried out in the flame of a hydrogen-oxygen torch, into which polydisperse aluminum oxide particles of diameters ranging from $0.1 \mu \mathrm{m}$ to $0.5 \mu \mathrm{m}$ were injected. The flame was optically thin. The temperatures of particles and flame were assumed as equal. The temperature of the flame was found from the $\mathrm{Na}$ emission line. The refractive index $n$ was not measured and its value $n=1.799$ was taken from the published sources for crystal $\mathrm{Al}_{2} \mathrm{O}_{3}$. The concentration of particles in the flame was determined based on the measurement of the particle's mass prior to the injection and was monitored during the experiment by measuring the scattering at different incident angles. The distribution of 
particles according to sizes was obtained by analysis of the collected particles using electron microscope. For testing of reliability of the obtained results additional measurement of transmission was carried out. There was an agreement between the values calculated on the basis of the results of both measurements of concentration of particles per unit of volume within the measurement errors. A total of 100-odd experiments were conducted at different temperatures of combustion products (and, therefore, particles). All the results were averaged, and the total result given in reference (Adams, 1967) was only one value of $\kappa=0.0074 \pm 0.0019$ (which corresponds to $\alpha=1580 \pm 400 \mathrm{~cm}^{-1}$ ) for the temperature range of $2500-2900 \mathrm{~K}$. The value of $\alpha$ shown in Figure 2 is that result obtained by Adams (1967). More, in that paper the results of five experiments at different temperatures were also given. Based on these results the following values of the absorption coefficient can be obtained: at $\mathrm{T}=2466 \mathrm{~K}$, $\alpha=919 \mathrm{~cm}^{-1}$; at $\mathrm{T}=2685 \mathrm{~K}, \alpha=1688 \mathrm{~cm}^{-1}$; at $\mathrm{T}=2700 \mathrm{~K}, \alpha=1795 \mathrm{~cm}^{-1}$, at $\mathrm{T}=2750 \mathrm{~K}, \alpha=1539 \mathrm{~cm}^{-1}$ and at $\mathrm{T}=2885 \mathrm{~K}, \alpha=2009 \mathrm{~cm}^{-1}$. Judging by these data, the absorption coefficient must have an increase temperature dependence. The values of $\alpha$, obtained by Adams, were much bigger than the results, obtained by Carlson.

In research by Mularz and Yuen (1972), the experiments were conducted with $\mathrm{Al}_{2} \mathrm{O}_{3}$ particles injected into a propane flame, where, in order to ensure necessary temperature, they used as an oxidant a mixture of oxygen with nitrogen or with argon. Although initially the characteristic particle sizes were of about $0.3 \mu \mathrm{m}$, due to agglomeration before injecting solid particles after melting in the flame, their size distribution was rather broad. The flame temperature was determined using the reversal method on a wavelength of $589 \mathrm{~nm}$ of sodium D line (for this purpose particles of $\mathrm{NaCl}$ salt were injected into the oxidizer path). In order to find the absorption index, $\kappa=\alpha \lambda / 4 \pi$, they registered the flux of self-emission of particles, and in order to determine concentration of particles per unit of volume and their sizes distribution, they measured the scattering of probing laser radiation. When investigating molten particles, emission intensity was measured at a distance of $22 \mathrm{~mm}$ from the torch. In reference (Mularz \& Yuen, 1972), the data are presented on absorption index of the molten aluminum oxide in the range from $0.35 \mu \mathrm{m}$ to $1.2 \mu \mathrm{m}$ at temperature of $2550 \mathrm{~K}$. The obtained values of the absorption coefficient are rather high, especially on the short-wavelength edge of the investigated range. High values of $\alpha$ were also obtained for solid particles. During the study of solid particles, their radiation was registered at a distance of $100-130 \mathrm{~mm}$ from the torch. For spheroidization by melting, the particles were injected into a more heated zone. Based on the experiments conducted that way, it was concluded that during the transition of particles from the molten to solid state no abrupt decrease of radiation occurred (and therefore in the absorption coefficient also), and the emissivity of particles monotonously decreased up to the lowest temperature, that is $1920 \mathrm{~K}$, during the studies. The results obtained by Mularz and Yuen (1972) for the absorption index $\kappa$ of solids were approximately by two orders higher than the data recommended for the crystal in (Lingart et al., 1982). In reference (Mularz \& Yuen, 1972), for example, at $\lambda=0.7 \mu \mathrm{m}$ and $\mathrm{T}=2090 \mathrm{~K}, \alpha=34.1 \mathrm{~cm}^{-1}$, whereas in (Lingart et al., 1982) at the same wavelength and $\mathrm{T}=2100 \mathrm{~K}, \alpha=0.29 \mathrm{~cm}^{-1}$. Mularz and Yuen explained the high values of $\alpha$ in the solid by the influence of impurities, although according to the supplier's information, the $\mathrm{Al}_{2} \mathrm{O}_{3}$ content in the powder was $99.9 \%$, and by the difference in structure from single-crystal $\mathrm{Al}_{2} \mathrm{O}_{3}$. Yet other explanations can be given for those results. For example, it can be assumed that the particles were not totally solidified, or there could be errors in determining their temperature, which was not measured directly, but was identified by gas temperature measured with the use of the reversal method of the sodium spectral line. Other reasons can be connected with the limited time of presence of melt in the gas flow, and the kinetics of transition from the short-range order of arrangement of atoms in the melt to the corundum structure.

In research by Bakhir et al. (1977), aluminized composite propellant was burned in a nitrogen atmosphere. The temperature of the flame was determined by the intensity of its emission and transmission at a wavelength of $4.5 \mu \mathrm{m}$. It was $2950 \mathrm{~K}$, and coincided with the calculated temperature of burning. The dependence of spectrum emission of the flame on the wavelength was measured in the experiment. The account of contribution of gaseous combustion products was found by way of calculation. The particle-size distribution was defined using electron and optical microscopes by way of analyzing particles captured from the combustion products. The chemical analysis of samples showed that $\mathrm{Al}_{2} \mathrm{O}_{3}$ particles constitute $98 \%$ of its mass, $1 \%$ is aluminum and $1 \%$ are impurities like other metal oxides particles. The error of defining of the absorption coefficient at wavelength $\lambda \leq 4 \mu \mathrm{m}$ was estimated as $\pm 30 \%$, while at longer wavelengths as $\pm 40 \%$.

In researches by Rubtsov and Emelyanov (1978), Rubtsov et al. (1984) and Rubtsov et al. (1988), there are results of experiments of determining of the absorption coefficient of monodisperse particles of molten aluminum oxide. The most detailed procedure for the experiment is in reference (Rubtsov \& Emelyanov, 1978). The spherical particles of diameter of $50 \pm 5 \mu \mathrm{m}$ were obtained by melting of aluminum oxide powder of corresponding sizes either using an oxygen-acetylene torch, or a plasma torch. It was found that the heating technique does not practically affect the optical properties being investigated. The absorption index was 
calculated on the basis of determining of the spectral emissivity, which, in turn, was calculated on the basis of measurement results of reflection and transmission of the flow of particles. Concentration of the particles in the flow was found from measurement of velocity and powder mass consumed over a certain period of time. The temperature of luminous particles was determined using a method of comparison of flow of particle radiation with radiation of a tungsten ribbon lamp, which served as a reference source. The measurements of $\kappa$ were performed in the wavelength range of 0.3-1.2 $\mu \mathrm{m}$. There were results for absorption of molten aluminum oxide for two temperatures: 2330 and $2440 \mathrm{~K}$. Based on the obtained results by Rubtsov and Emelyanov (1978), Rubtsov et al. (1984), and Rubtsov et al. (1988), like Mularz and Yuen (1972), the conclusion was made that during melting the absorption index of $\mathrm{Al}_{2} \mathrm{O}_{3}$ does not change abruptly, but increases monotonously with temperature rise, and this is typical for a polycrystalline aluminum oxide, obtained by way of crystallization of molten droplets. The abrupt increase of $\mathrm{K}$ during melting, according to the authors of references (Rubtsov \& Emelyanov, 1978; Rubtsov et al., 1984; Rubtsov et al., 1988), is characteristic only for a single crystal. It should be noted, however, that the optical properties of polycrystalline particles in these researches, as well as in research (Mularz \& Yuen, 1972), were measured after the crystallization of the molten droplets in the flow at a certain distance from a plasma torch or plasmatron, that is, not prior to the melting, but after solidification, and so, the $\kappa$ values for solid particles at the near melting temperature are much larger than the values characteristic for single-crystal corundum. And here also the influence of some factors could be assumed such as incomplete solidification of the particles, a difference of crystal structure from corundum lattice, the influence of burning products or products of decomposition of the plasma torch electrodes and others factors.

In research by Konopka et al. (1984) there are results, in the range 1700-3000 K and wavelengths from $1.3 \mu \mathrm{m}$ to $4.5 \mu \mathrm{m}$, of optical properties of submicron particles (an average radius of $0.1 \mu \mathrm{m}$ ) of aluminum oxide, obtained by capturing in the combustion products of two different full-scale solid-fuel rocket motors. The particles from rocket 1 were captured from the core of the flow and outwardly looked gray. The particles from rocket 2 were captured along a streamline tangent to the nozzle wall, and outwardly looked brown. The measurements of the optical properties were performed on aerosols $\left(\mathrm{Al}_{2} \mathrm{O}_{3}\right.$ particles in argon), produced in the reflection zone of a conventional shock tube. The temperature of the particles was calculated with an accuracy of $\pm 3 \%$. As the authors of reference (Konopka et al., 1984) noted, the agglomeration of the particles did not occur, the cold walls of the shock tube allowed to conduct measurements of the intensity of weak emission of aerosol with the least impact of emission and reflection of the environment. The spectral emissivity was measured at 8 discrete values of wavelengths in the range from $1.5 \mu \mathrm{m}$ to $4.5 \mu \mathrm{m}$ (wide-band filters) using a spectrometer and three radiometers operating with narrow-band filters at wavelengths of $1.3 \mu \mathrm{m}, 3.3 \mu \mathrm{m}$ and $4.5 \mu \mathrm{m}$. In addition, they measured a direct transmission at wavelengths of $0.488 \mu \mathrm{m}, 3.39 \mu \mathrm{m}$ and $0.632 \mu \mathrm{m}$. In each experiment, the parameters of the shock tube were chosen in such a way so that to ensure, at the desired temperature of particles, an optical thickness of the aerosol cloud of slightly less than 1 . The particle size distribution was defined using two methods. One is measuring transmission directly in the experiment (at the three mentioned above wavelengths of laser radiation), the other is based on automatic analysis by an electron microscope of particles directly collected during the experiment. Free aluminum was discovered in the particles, however, its amount was not found. Besides, the spectral analysis (atomic emission spectroscopy) of the particles from the two rocket motors revealed a large amount of impurities of different metals. Their total amount in the particles from rocket 1 reached $2 \%$ in mass. For rocket 2 it was much larger. Therefore, we present in Figure 2 the data only for the particles from rocket 1 . The content of carbon in particles was below the defined limit of $0.05 \%$ per mass. The authors of research (Konopka et al., 1984) note that because of a rather large error in the measurement of temperature, they cannot be sure whether the data received at $2375 \mathrm{~K}$ refer to a liquid or a solid phase. Most probably, the particles were partially molten. Because in the two methods of measurement by Konopka et al., (1984) the difference in determining of the particle size distributions is significant, the two values of the absorption index are given, calculated for each distribution. Using the distribution obtained from measurements of transmission of probe laser radiation, the average value of the absorption index is one and a half times larger. We have calculated the values of the absorption coefficient $\alpha$, shown in Figure 2, based on the average value of the two values of $\kappa$, given in reference (Konopka et al., 1984). If the results for $2375 \mathrm{~K}$ are disregarded, then, according to (Konopka et al., 1984), the absorption coefficient of molten particles captured from rocket motor exhausts does not much depend on temperature. It is noted in this study that for less contaminated particles from rocket 1 an abrupt discontinuous increase was observed in the absorption coefficient, during transition from solid to melt, while more contaminated particles from rocket 2 it was not. Also in reference (Konopka et al., 1984), there are data of another study of absorption index in experiments with particles of pure commercial aluminum oxide at $2700 \mathrm{~K}$. The corresponding values of $\alpha$ are shown in Figure 2. These values are higher than those for particles captured from the rocket motor exhausts. The authors of reference (Konopka et al., 1984) note that in 
that study there are many uncertainties connected with, for example, a difficulty in determining of particle size distribution.

And the latest published work, known to us, on determination of the absorption coefficient of molten $\mathrm{Al}_{2} \mathrm{O}_{3}$ from experiments with particles was in 1991 (Parry \& Brewster, 1991). The experimental procedure and characterization of particles are described in the previous section. The result of the study is presented in Figure 2 - the two points on wavelengths of $0.6328 \mu \mathrm{m}$ and $1.064 \mu \mathrm{m}$, obtained at a temperature of $2680 \mathrm{~K}$.

\section{Absorption Coefficient (Absorption Index) of Thick Molten Layers of Aluminum Oxide}

Probably, the first results of the investigation of the absorption coefficient of molten $\mathrm{Al}_{2} \mathrm{O}_{3}$, conducted not with the molten droplets in the flow of combustion products, flame or plasma, but with sufficiently thick molten layers, were published in (Shigapov et al., 1978). These results are presented in details in (Shigapov and Zykov, 1979; Shigapov, 1998). Unfortunately, in those papers there is no data on the composition and content of impurities in $\mathrm{Al}_{2} \mathrm{O}_{3}$, used for preparation of the melt. From the review by (Shigapov, 1998), it can be concluded that a chemically pure aluminum oxide was used for preparation of the melt. The lens of the melt was held by surface tension forces in a round hole of a special cell made of tungsten sheet. The thickness of the melt varied from $0.1 \mathrm{~mm}$ to $1 \mathrm{~mm}$. The absorption coefficient was determined on the basis of measurements of the transmittance. The intensity of intrinsic emitted radiation is subtracted from the sum total of intensity of transmitted and emitted radiation. As follows from (Shigapov, 1998), the main problem in such measurements is elimination of interaction of molten $\mathrm{Al}_{2} \mathrm{O}_{3}$ with tungsten. It is said that "preliminary degassing of the vacuum chamber, registered by vacuum gauges, does not ensure the success of the experiments. When a gas release finishes, which is indicated by control devices, it is required about 10 hours for heating of the chamber, the heater's temperature being approximately $2000 \mathrm{~K}$. After such a thorough degassing, molten $\mathrm{Al}_{2} \mathrm{O}_{3}$ does not come into reaction with tungsten". The experimental data presented in (Shigapov, 1998) cover temperature of 2400 $2700 \mathrm{~K}$ for two wavelengths of the probe laser radiation, i.e. $0.63 \mu \mathrm{m}$ and $1.15 \mu \mathrm{m}$. Nothing is said about the composition of the environment during the measurements. By some indirect signs it can be assumed that the measurements were performed in vacuum. According to the results the difference between the absorption coefficient of the molten $\mathrm{Al}_{2} \mathrm{O}_{3}$ and absorption coefficient of single crystal $\mathrm{Al}_{2} \mathrm{O}_{3}$ near the melting temperature constitutes four orders of magnitude. The values in (Shigapov, 1998) are much higher than the values in the earlier published paper (Shigapov et al., 1978). Figure 2 shows the results given in (Shigapov, 1998). In addition to the experimental data, in (Shigapov, 1998) there are calculated data on the temperature dependence of $\kappa$ for wavelengths of $3 \mu \mathrm{m}$ and $6 \mu \mathrm{m}$. Regrettably, the details of this calculation are not known. These data are also shown in Figure 2.

The year of 1988 saw the publication of the first result on determination of the absorption coefficient for molten $\mathrm{Al}_{2} \mathrm{O}_{3}$ obtained in experiments with partially molten single-crystal fiber (Abrevaya \& Nordine, 1988). Measurements were carried in a weak flow of high purity argon. The fiber of $0.25 \mathrm{~mm}$ in diameter was heated on the one side by radiation of $\mathrm{CO}_{2}$ laser. The results were obtained by measuring the spectral emissivity, or, to be more exact, by the brightness temperature for the wavelength of a pyrometer equaling to $0.665 \mu \mathrm{m}$ at the melting temperature (the middle part of the fiber has just been melted). The heated and molten part of the fiber was in contact with non-molten part. The value of $\alpha$ was $12 \pm 2 \mathrm{~cm}^{-1}$.

In (Nason et al., 1990), the absorption coefficient of melts of various oxides, including aluminum oxide, for a wavelength of $0.6328 \mu \mathrm{m}$ of He-Ne laser was determined by measuring transmission and reflection. The molten zone in the middle of a single-crystal fiber of about $1 \mathrm{~mm}$ in diameter or a spherical droplet at its end were produced by laser heating. The environment, in which the measurements were carried out, was not specified. There was obtained one point at temperature approximately $2473 \mathrm{~K}$ for molten $\mathrm{Al}_{2} \mathrm{O}_{3}$. The value of the absorption coefficient was $5 \mathrm{~cm}^{-1}$.

A thorough investigation of the absorption coefficient for molten $\mathrm{Al}_{2} \mathrm{O}_{3}$ being in contact with the solid phase was made by Weber, Krishnan et al. (1995). The experiments were performed with a single crystal sapphire fiber of $0.25 \mathrm{~mm}$ in diameter. The mass of impurities of different metal elements was about $0.01 \%$. The fiber had some voids of about $1 \mu \mathrm{m}$ in diameter. Placed horizontally, the fiber was heated on the top by $\mathrm{CO}_{2}$ laser radiation. During the experiments the blowing of different gases under pressure of 40-70 Pa was ensured by simultaneous work of a valve and a vacuum pump. The temperature condition was kept steady and the upper part of the fiber was in the molten state. The emission spectrum of the molten area in horizontal direction was registered. The radiation intensity of the melt was compared to the radiation intensity of the tungsten ribbon lamp, placed instead of the fiber, which served as a reference standard for calculation of spectral emissivity $\varepsilon_{\lambda}$. The emissivity was calculated on the basis of the brightness temperatures measured by spectrometer, assuming that the true 
temperature of the melt was equal to the melting temperature of $2327 \mathrm{~K}$. Based on this calculation of $\varepsilon_{\lambda}$ and determining of the melt's thickness through its observation, using a pyrometer, the absorption coefficient was found. The data were received in the wavelength range from $0.3 \mu \mathrm{m}$ to $0.8 \mu \mathrm{m}$. The ordinary values of $\varepsilon_{\lambda}$ were in the range from 0.2 to 0.5 . A large difference (4-6 times) was found in the values of $\alpha$ in measurements carried out in oxygen and argon (Figure 2). In addition, the absorption coefficient was measured in an atmosphere of $10 \%$ $\mathrm{H}_{2}+90 \% \mathrm{~N}_{2}$. The obtained value was about 1.5 times higher than in argon. During heating and melting and during change of the blowing gas some peculiar features were observed in the $\mathrm{Al}_{2} \mathrm{O}_{3}$ behavior. The results showed that absorption coefficient after melting changed significantly and after some time it reached stable values, which were different for different ambient conditions. For example, when ambient conditions changed from argon to oxygen, the absorption coefficient of a sapphire fiber of $0.25 \mathrm{~mm}$ diameter stabilized after about 30 minutes. Thus, it was found that the absorption coefficient in oxygen was 4-6 times higher than in argon. The long-wavelength edge of the electronic absorption in oxygen shifted towards the long wavelength region.

In research by Vorobyev et al. (1999), the absorption coefficient of molten $\mathrm{Al}_{2} \mathrm{O}_{3}$ was measured by method of thermal waves. The ceramic samples, in the form of $50-\mathrm{mm}$ discs, were heated by $\mathrm{CO}_{2}$ laser radiation in ambient air. The radiation flux could be oscillated within a wide range of frequency from $3 \mathrm{~Hz}$ to $300 \mathrm{~Hz}$. The oscillation frequency was chosen in such a way that the length of a heating wave was much smaller than the thickness of the melt. The thickness of the pool of melt in the middle of the ceramic sample was as a rule 1-2 $\mathrm{mm}$. Based on the shifts in phases between the oscillating $\mathrm{CO}_{2}$ laser radiation heating (almost surface heating) and the radiation coming from the melt of the chosen wavelength, it became possible to determine the value of the absorption coefficient, since it's this value that determined the depth of the layer from which radiation was emitted. The experimental data on the shifts in phases were compared with the calculated data obtained as a result of solving a direct problem of radiative-conductive heat transfer in a molten layer, when different values of absorption coefficients were set, and the most appropriate value of absorption coefficient was chosen. The data on the absorption coefficient were obtained for two temperatures -2500 and $2700 \mathrm{~K}$. The material for the melt was ceramics, which was obtained by a conventional method of cold pressing and subsequent sintering. The impurity content was not analyzed.

In research by Brun et al. (2003), along with the spectral emissivity of a single crystal of aluminum oxide measurement was also made of the spectral emissivity of its melt at the near-melting temperature. During measurements of $\varepsilon_{\lambda}$ samples were heated by $\mathrm{CO}_{2}$ laser radiation in the ambient air. The results were obtained at wavelengths from $1.7 \mu \mathrm{m}$ to $28 \mu \mathrm{m}$, thus covering both semitransparent and nontransparent regions. Although the main aim of this research was to study the premelting effect, i.e., a substantial increase in the emissivity of a single crystal at the near-melting temperature, using the presented data on $\varepsilon_{\lambda}$ at 2320,2340 and $2360 \mathrm{~K}$ the absorption coefficient of the melt can be calculated. From additional information (Brun, 2003), by courtesy provided by Dr. Brun, the melt was formed in the middle of a $1 \mathrm{~mm}$ thick single crystal sample by laser heating on both sides and was held by forces of viscosity. We have calculated the absorption coefficient values on the basis of experimental data for $\varepsilon_{\lambda}$ in reference (Brun et al., 2003) in the semitransparent region, which are shown in Figure 2. It can be seen that the values of $\alpha$ are quite low, having the minimum values between $2.5 \mu \mathrm{m}$ and 3 $\mu \mathrm{m}$.

In research by Sarou-Kanian et al. (2005), the spectral emissivity of an $\mathrm{Al}_{2} \mathrm{O}_{3}$ molten droplet of about $3 \mathrm{~mm}$ in diameter, freely cooled from temperature of approximately $3000 \mathrm{~K}$, was studied under aerodynamic levitation conditions. The droplet was heated by direct radiation, falling from $\mathrm{CO}_{2}$ laser from above, and by its radiation from below, that was reflected from the nozzle walls. The temperature on the surface of the droplet was measured from above by a pyrometer, with a filter for a bandwidth from 8.5 to $9.5 \mu \mathrm{m}$ at maximum of $9 \mu \mathrm{m}$. It was assumed that at $9 \mu \mathrm{m}$ the emissivity of the surface was 0.999 . The observed supercooling could exceed $200 \mathrm{~K}$. The reference signal for the pyrometer was the maximum signal after recalescence (the beginning of a slight sloping solidification plateau), which was in agreement with the solidification temperature of $2327 \mathrm{~K}$. In the quasi-steady state, before cooling, the temperature difference between the top and bottom of the droplet could reach up to $200 \mathrm{~K}$. The authors believe that about $100 \mathrm{~ms}$ after the beginning of the cooling, the temperature in the volume of the droplet equalized. The levitation was realized in oxygen, argon and a mixture of $\mathrm{Ar}+5 \% \mathrm{H}_{2}$. It was found that at the levitation in argon or its mixture with hydrogen, the molten droplet is opaque for all temperatures and it is characterized by very slight supercooling or none at all. For the levitation in oxygen there are data in (Sarou-Kanian et al., 2005) concerning the spectral emissivity in the range from $2 \mu \mathrm{m}$ to $6 \mu \mathrm{m}$, at temperatures $2800,2500,2300$ and $2100 \mathrm{~K}$. The two latter temperatures refer to the supercooled state, where supercooling for the first of them is, in fact, very small. It's worth noting that at wavelengths exceeding approximately $4.7 \mu \mathrm{m}$, the curves for all the temperatures within the measurement error coincide. In the part with 
short wavelengths, the values of $\varepsilon_{\lambda}$ for temperatures $2500 \mathrm{~K}$ and $2800 \mathrm{~K}$ are very close, and exceed 0.9 , which allow to speak of the presence in the droplet of an optically infinite layer, at these temperatures. Therefore, for the calculation of the spectral absorption coefficient of the melt, we actually could take from reference (Sarou-Kanian et al., 2005) the results of $\varepsilon_{\lambda}$ only referring to $2300 \mathrm{~K}$. The results of our calculations are shown in Figure 2.

In addition to the above results, there were data in reference (Sarou-Kanian et al., 2005) on the dependence on temperature of the spectral emissivity $\varepsilon_{\lambda}$ and the absorption index $\kappa$ for a wavelength of $3 \mu \mathrm{m}$. These data include the zone of the melt (from 2800 to $2327 \mathrm{~K}$ ), of the supercooled melt (from 2327 to $2070 \mathrm{~K}$ ), the intermediate zone near the solidification temperature (from 2327 to $2200 \mathrm{~K}$ ) and the zone of the solid phase from $2200 \mathrm{~K}$ to $1500 \mathrm{~K}$. The nature of changes of $\varepsilon_{\lambda}$ and $\mathrm{K}$ with temperature looks different in all these zones. Figure 3 shows the dependence of the absorption coefficient $\alpha$ on temperature, which we have calculated on the basis of data of reference (Sarou-Kanian et al., 2005) using $\kappa$, obtained at heating and cooling in oxygen. In the range from 2580 to $2800 \mathrm{~K}$ (section 1) the absorption coefficient decreases with temperature. This could hardly be explained by any physical reason. It may probably be just due to an error of the experiment, which, with the increase of $\alpha$ with temperature, becomes larger when approaching to the optically infinite layer. The optical thickness of the droplet at $2580 \mathrm{~K}$ was already 4.2. At much lower temperatures, up to the maximum supercooling (sections 2 and 3), $\alpha$ varies with temperature monotonously. Returning from the supercooled state, the absorption coefficient with temperature (section 4) decreases much abruptly than at the same temperatures in the supercooled melt. Considering that this fact needs further investigation, the authors of reference (Sarou-Kanian et al., 2005) note that after recalescence in the course of solidification the droplet has a mixed liquid-solid phase with a thick solid layer, growing from the surface, which may have such optical properties that differ from the properties of liquid and solid phases. However, at temperatures lower than $2200 \mathrm{~K}$ the rate of decrease of the absorption coefficient becomes smaller with decreasing of temperature and shows the dependence which is typical for sapphire.

A rather concise characteristic by the authors of reference (Sarou-Kanian et al., 2005) of the process of solidifying of a droplet raises more questions than answers. It should be noted that the formation of a broad two-phase zone at solidification of $\mathrm{Al}_{2} \mathrm{O}_{3}$ was for the first time discovered by numerical calculation in the work (Petrov, Titov \& Vorobyev, 1999) and then confirmed experimentally by Vorobyev, Petrov, Titov and Fortov (2001). It was shown that the two-phase zone formation took place in the process of crystallization. The nature of dendritic crystal growth in the subsurface layer suggests that dendrites grew from the surface into the supercooled melt and expanded into the melt between individual dendrites. The transition from the dendritic growth to the growth of roughly isometric grains was associated with the decrease of the cooling rate in deeper layers of the melt.

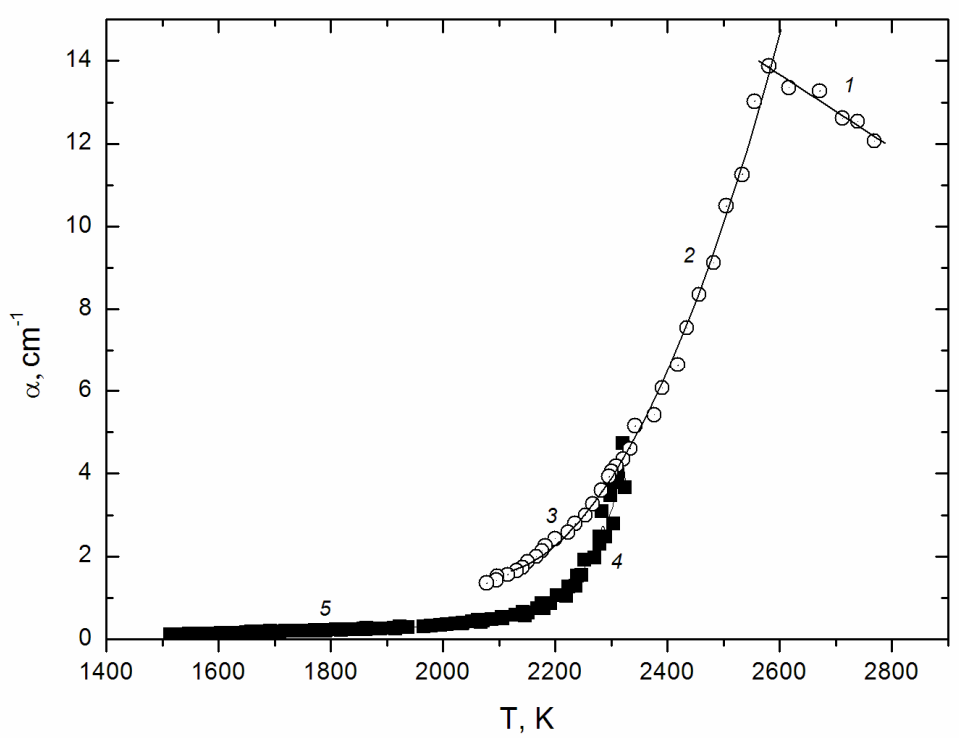

Figure 3. Absorption coefficient of $\mathrm{Al}_{2} \mathrm{O}_{3}$ at $3 \mu \mathrm{m}$, calculated from data on $\kappa$, obtained by Sarou-Kanian et al. (2005) in the course of cooling in oxygen 
1,2 and 3 - melt and supercooled melt; 4 and 5 - two-phase region and solid phase.

Meanwhile, on the issue of rapid solidification of the molten $\mathrm{Al}_{2} \mathrm{O}_{3}$ there are two quite different views up to date. One is that in the course of solidification a crystalline $\gamma$-phase is formed, which after further cooling transfers very rapidly into an equilibrium $\alpha$-phase (Levi et al., 1988; Anfimov et al., 1993; Plastinin et al., 2000). The other view is that in the course of the rapid crystallization a two-phase extended zone is formed (Vorobyev et al., 2001; Vorob'ev et al., 2007). But we are not going to discuss them here, as it is beyond the subject of this review.

\section{Molten Aluminum Oxide Structure and Physicochemical Processes Influencing the Absorption Coefficient}

For a long time scientists have been showing considerable interest to big differences in the values characterizing various thermal and optical properties of the molten and crystal of aluminum oxide at near-melting temperature, and it encouraged them to look into the causes of this phenomenon. First, the researchers focused their efforts on studying the changes in the nature of a relative location of atoms of oxygen and aluminum in the phase transition. The melting point of $\mathrm{Al}_{2} \mathrm{O}_{3}$ is relatively low compared with other major refractory oxides, this facilitates the setting of tasks and doing the research. About fifty years ago, it was found that spray deposition by flame (Ault, 1957) and plasma (Thompson \& Whittemore, 1968) formed the $\gamma$-aluminum oxide with less density than corundum. The receipt and further holding of this non-equilibrium structure is, of course, connected with a high speed of cooling of molten particles during spraying, however, it is the formation of the $\gamma$-form, that can speak of the corresponding short-range order in arrangement of atoms in the melt. On the other hand, direct X-ray measurements of the structure of the melt, contacting a crystal, at a temperature of the melt, close to the melting temperature (Nukui, Tagai, Morikava, \& Iwai, 1976), showed that the short-range order of arrangement of atoms corresponds to the corundum structure. In the corundum structure, each aluminum atom is surrounded by six oxygen atoms and is in the octahedral node. In the non equilibrium structure $\gamma-\mathrm{Al}_{2} \mathrm{O}_{3}$, aluminum atoms are mainly in tetrahedral coordination. The study of solidification of the molten droplet of several $\mathrm{mm}$ in diameter, suspended in a free state by means of aerodynamic levitation (Coutures, Rifflet, Florian, \& Massiot, 1994) in different gases, has revealed a significant impact of the gaseous medium. The NMR studies in the melt in (Coutures et al., 1994), show that the aluminum ions can be tetra-, penta- and hexa- coordinated. At $2400 \mathrm{~K}$ the numbers of ions in the above coordinations are $20 \%, 60 \%$ and $20 \%$, respectively. The average coordination number is 4.94 .

Lately several successful investigations have been carried out in this direction. These are experimental studies (Waseda, Sugiyama, \& Toguri, 1995; Ansell, Krishnan, Weber, Felten, \& Nordine, 1997; Landron, Hennet, \& Thiaudiere, 2001; Landron, Hennet et al., 2001; Landron, Soper et al., 2001; Krishnan et al., 2005) and molecular dynamics simulations (San Miguel, Sanz, Fernandes, Alvares, \& Ordiozola, 1998; Gutierres, Belonoshko, Ahuja, \& Johansson, 2000; Ahuja et al., 2004; Vashishta, Kalia, Nakano, \& Rino, 2008). Although there are some disagreements between various studies, in most of them, except (Waseda et al., 1995), the conclusion is made that the short-range order in molten alumina is essentially defined by a $\left(\mathrm{AlO}_{4}\right)^{5-}$ basic unit, i. e., liquid $\mathrm{Al}_{2} \mathrm{O}_{3}$ shows $\gamma$-phase-like coordination. If this is the case, most likely it is the reason for the high value of the absorption coefficient of molten alumina. As is calculated in (Ahuja et al., 2004), the band gap for the $\gamma$-phase of alumina at room temperature can be equal to $3.9 \mathrm{eV}$ (in comparison to $8.8 \mathrm{eV}$ for the $\alpha$-phase). So the melt may be considered as a semiconductor with a narrow band gap, especially at high temperatures, and it can have a large absorption coefficient over a broad wavelength range.

It should be noted that all experimental studies of the short-range atomic order in molten alumina were carried out in steady-state conditions, and the time duration for alumina being in the molten state amounted to minutes or tens of minutes. The transient process for the structural change was not studied.

It was observed in (Coutures et al., 1994) that the structure depends on the partial pressure of oxygen in the environment. The experiments in argon showed that free aluminum atoms may appear in the melt. At $2620 \mathrm{~K}$ the concentration of such free aluminum atoms is about $2.5 \%$, and they act like nuclei at crystallization. The equilibrium concentration of free aluminum atoms in the melt decreases abruptly with the decrease of temperature $(0.3 \%$ at $2473 \mathrm{~K})$.

In the experiments with droplet solidification in argon, the formation of the central cavity was observed, and in oxygen - an increase of a ball volume compared to a droplet and appearance of cracks and pores. In research by Coutures et al. (1994) it is believed that this is a release of dissolved oxygen influence. Below is schematically shown the dissolution of oxygen: 


$$
\begin{gathered}
\mathrm{O}_{2}(\mathrm{~g}) \rightarrow 2 \mathrm{O}(\mathrm{l}), \\
2\left(\mathrm{AlO}_{4}\right)^{5-}+\mathrm{O} \rightarrow\left(\mathrm{Al}_{2} \mathrm{O}_{8}\right)^{8-}+\mathrm{O}^{2-} .
\end{gathered}
$$

The subject of investigation in reference (Ansell et al., 1997) was the structure of molten $\mathrm{Al}_{2} \mathrm{O}_{3}$ in normal and supercooled state. The experiments were carried out using diffraction of X-ray synchrotron radiation. Droplets of 3-4 $\mathrm{mm}$ in diameter were suspended also by aerodynamic levitation in different gases (air, oxygen, nitrogen) and were heated by $\mathrm{CO}_{2}$ laser radiation. The temperature range in the studies was $2200-2700 \mathrm{~K}$. The results in (Ansell et al., 1997) show that the melting of $\alpha-\mathrm{Al}_{2} \mathrm{O}_{3}$ affects radically the structure and coordination. In the melt, the $\mathrm{Al}-\mathrm{O}$ coordination number is 4.4, i.e., $\left(\mathrm{AlO}_{4}\right)^{5-}$ tetrahedrons (the basis of the melt structure) contact with other tetrahedrons, and so the structure is like $\gamma-\mathrm{Al}_{2} \mathrm{O}_{3}$. This structure does not change considerably with temperature and remains in the supercooled liquid. There has been expressed an assumption in (Ansell et al., 1997) that the existence of a structure in the melt similar to $\gamma-\mathrm{Al}_{2} \mathrm{O}_{3}$ makes possible an intermediate metastable $\gamma$-phase in the course of solidification. In reference (Krishnan et al., 2005), the results are more recent, a similar method was used, heating a droplet in argon and oxygen. In both cases, the melt structure had little differences, though the differences in the optical properties were large.

The influence of the environment on the absorption coefficient of the melt is a principal issue. There have been made not so many direct measurements of this effect. In research by Weber, Krishnan et al. (1995), measurements were made with a thin molten zone of sapphire fibers. These studies are described in the 4-th section. The measurement method in Weber, Nordine et al. (1995) was different. The samples had a shape of sphere of $2.5 \mathrm{~mm}$ in diameter and were made of Verneuil sapphire crystals, which were welded to the sapphire fiber of $0.5 \mathrm{~mm}$ in diameter and 2-3 cm long. In some samples, impurities of $\mathrm{Si}, \mathrm{Mg}, \mathrm{Fe}, \mathrm{W}$ were intentionally introduced into the melt, the mass of which constituted $0.5-1 \%$. The measurements of the absorption coefficient were carried out on the pendant molten droplet heated by $\mathrm{CO}_{2}$ laser, using a method of measuring of the dye laser radiation transmittance (wavelengths of $0.45 \mu \mathrm{m}$ and $0.633 \mu \mathrm{m}$ ). The experiments were performed in the flow of pure gases of $\mathrm{Ar}, \mathrm{O}_{2}, \mathrm{CO}, \mathrm{CO}_{2}, \mathrm{H}_{2}$ and $\mathrm{N}_{2}$ at a pressure of $1 \mathrm{bar}$, as well as in the flow of mixtures of $\mathrm{HCl}$ and $\mathrm{CO} / \mathrm{CO}_{2}, \mathrm{H}_{2} / \mathrm{H}_{2} \mathrm{O}$ lower pressures. The probing radiation passed through the sample path where the temperature varied from about 2370 to $2450 \mathrm{~K}$. The authors refer the obtained results to an average temperature of $2400 \mathrm{~K}$. It was found that in the gas mixtures of $\mathrm{CO} / \mathrm{CO}_{2}$ and $\mathrm{H}_{2} / \mathrm{H}_{2} \mathrm{O}$ the absorption coefficient strongly depends on partial pressure of oxygen in ambient gas. Its value varies from $55 \mathrm{~cm}^{-1}$ to $20 \mathrm{~cm}^{-1}$. In pure argon, nitrogen and $\mathrm{CO}$ the value is $\alpha \approx 53-55 \mathrm{~cm}^{-1}$, whereas in pure $\mathrm{O}_{2}, \mathrm{CO}_{2}$ and $\mathrm{H}_{2} \mathrm{O}$ the value is $\alpha \approx 20-30 \mathrm{~cm}^{-1}$. There are certain differences in the results of references Weber, Krishnan et al. (1995) and Weber, Nordine et al. (1995). In particular, for the absorption coefficient at the wavelength of $0.633 \mu \mathrm{m}$ measured in argon (Weber, Nordine et al., 1995) the obtained result is $\alpha \approx 50-60 \mathrm{~cm}^{-1}$, whereas in (Weber, Krishnan et al. 1995) it is $\alpha=$ $9 \pm 2 \mathrm{~cm}^{-1}$. In oxygen the values are $\alpha \approx 20-30 \mathrm{~cm}^{-1}$ and $41 \pm 8 \mathrm{~cm}^{-1}$, correspondingly. It should be mentioned, however, that the results presented in these studies, were obtained at different temperatures. Moreover, in the experiments with blowing oxygen, the pressures were different. In (Weber, Krishnan et al. 1995) it was 40-70 Pa, and in (Weber, Nordine et al., 1995) $-10^{5} \mathrm{~Pa}$. The authors explain the obtained dependence of $\alpha$ on partial pressure of oxygen in mixtures by deviations from stoichiometry. They also came to the conclusion that partial pressure of oxygen in gas mixtures, at which minimal absorption was observed, depends on temperature. The pressure, at which the absorption is minimal, increases with temperature. At $2400 \mathrm{~K}$ the partial pressure is about $10^{-4}$ bar. A hypothesis was suggested (Weber, Nordine et al., 1995) in this connection, that the decrease in absorption, as partial pressure of oxygen increases, tends to move towards stoichiometry, and an increase in absorption, at higher pressures, tends to increase dissolution of oxygen.

The results received by Weber, Nordine et al. (1995) show that impurities of silicon, magnesium, iron, tungsten, amounting of $0.5-1 \%$, made the droplet opaque, that is, the absorption coefficient $\alpha$ was more than $55 \mathrm{~cm}^{-1}$.

The results of measurement of the emissivity of a molten droplet in argon, presented in reference (Sarou-Kanian et al., 2005), definitely show that the absorption coefficient in argon is larger than in oxygen. A droplet of about $3 \mathrm{~mm}$ in diameter was opaque in the entire range of studied wavelengths. Indirect results of higher values of the absorption coefficient in argon compared with oxygen can be found in reference (Coutures et al., 1994 and Nelson, Richardson, Keil, \& Skaggs, 1973). This suggests a possible error in the data published in reference (Weber, Krishnan et al., 1995) in the ratio of the absorption coefficient values of the melt in oxygen and argon.

In addition to direct studies (Weber, Krishnan et al. 1995; Weber, Nordine et al., 1995) of influence of environment on the absorption coefficient, there is a number of indirect observations related to this issue. Such indirect observation are the studies of solidification in the course of cooling of the melt. In the study by Nelson et al. (1973) the process of solidification of a pendant droplet of molten $\mathrm{Al}_{2} \mathrm{O}_{3}$ in oxygen and argon was specially 
investigated. The melt was obtained from a single crystal sapphire. The droplet's diameter was around $2.5 \mathrm{~mm}$. It was found out that in order to preserve the droplet in the "just - melted state" in oxygen, $\mathrm{CO}_{2}$ heating laser power is required about $20 \%$ less compared with the same condition in argon. The brightness of such a droplet in oxygen, at a wavelength of $0.66 \mu \mathrm{m}$, was $37 \%$ lower than in argon. The character of crystallization in these two gases was different, too. It was suggested that aluminum oxide becomes oxygen-rich in oxygen and oxygen-deficient in argon. The character of crystallization was such that in argon it started from the surface, layer after layer, as temperature was decreasing. In oxygen, due to a smaller absorption coefficient, the heat transfer had a volumetric character, crystallization was going over the volume. When crystallization was going from the supercooled state (the value of supercooling is much smaller than that of a freely suspended droplet in aerodynamic levitation) the excessive metal or oxygen could remove from the melt and the solidified substance was getting a gray color in argon, or "gurgling" and lamellar voids in oxygen.

The solidification of droplets in non-contact conditions (aerodynamic levitation in oxygen or argon) was studied with the help of NMR (Coutures et al., 1994). Supercooling in oxygen reached $275 \mathrm{~K}$, and in argon it was in the range of 50-175 K. The authors of reference (Coutures et al., 1994) associated the lower supercooling in argon with metal aluminum atoms found in the melt with the help of NMR, whose concentration increased with temperature. As the temperature of the melt in quasi-stationary state prior cooling in argon increased, the nucleation temperature also increased to be $2153 \mathrm{~K}$ when cooling from $2723 \mathrm{~K}$, and $2253 \mathrm{~K}$ when cooling from $2900 \mathrm{~K}$. The density of molten $\mathrm{Al}_{2} \mathrm{O}_{3}$ also was obtained in argon higher than in oxygen. Atoms of aluminum are nuclei at crystallization in argon. The evaluation showed that at $2623 \mathrm{~K}$ the concentration of free atoms of $\mathrm{Al}$ in argon is about $2.5 \%$.

In research by Vorob'ev et al. (2007), the reflectivity of molten pool on the surface of a ceramic sample in vacuum was also less than the values obtained in similar conditions when measured in air, that is, the absorption coefficient of the melt in vacuum is larger.

There are some other works, indirectly addressing the problem of differences in the absorption coefficient of molten $\mathrm{Al}_{2} \mathrm{O}_{3}$ and crystal at near-melting temperature, which studied a slow solidification process when crystals were grown from the melt. It that cases it frequently happened that the growing crystal was capturing gas bubbles from the melt. There are different views on the nature of this phenomenon. In reference (Bagdasarov, 2004) it is explained by thermal dissociation of evaporating products of $\mathrm{Al}_{2} \mathrm{O}_{3}$. This can lead to large values of the absorption coefficient in comparison with the crystal, since preferential evaporation of $\mathrm{Al}$ atoms can cause violation of stoichiometry of the melt and thereby cause defects in the local order of arrangement of atoms.

Since the droplets of molten aluminum oxide play a crucial role in the flame radiation of solid fuel rocket motors, there have been made numerous attempts to investigate the influence of gas combustion products on the optical and other properties of these droplets. This issue has not been given explicit explanation so far. In research by Gosse et al. (2003), for the analysis they took solidified particles from the combustion products of a small-scale model of solid propellant rocket motor. The particles were of a diameter from $0.1 \mu \mathrm{m}$ to $20 \mu \mathrm{m}$. There were found many hollow microspheres among them. It was also found that from all particles, $25 \%$ were those with the crystal lattice of $\alpha-\mathrm{Al}_{2} \mathrm{O}_{3}$, while the particles with a cubic lattice amounted to $75 \%$. The authors of reference (Gosse et al., 2003) suggested that the latter were oxynitrides which were formed owing to the presence of nitrogen in the combustion products. The formation of hollow microspheres was explained by a large amount of water steam emerging during burning of solid fuel, and its high solubility in liquid alumina and spitting during liquid-to-solid transition, followed by removing of nitrogen during solidification of droplets. Later, some ideas about the phenomena described above changed, which found its reflection in (Gosse, Hespel, Gossart, \& Delfour, 2006). For example, particles with a cubic lattice in reference (Gosse et al., 2003) were already considered as $\gamma-\mathrm{Al}_{2} \mathrm{O}_{3}$ particles, and the amount of detectable hollow microspheres became much less.

\section{Comparison of Available Data on the Absorption Coefficient}

Analyzing all the data available in the published literature on the absorption coefficient of molten $\mathrm{Al}_{2} \mathrm{O}_{3}$ (Figure 2), it can be said that in general the range of values $\alpha$ is very big - from less than a dozen $\mathrm{cm}^{-1}$ to $1000 \mathrm{~cm}^{-1}$. Based of the above analysis of individual studies we can point out two groups of results.

One group is where the highest values of $\alpha$ have been obtained in experiments with particles, carried out in operating conditions of solid fuel rocket motors (Parry \& Brewster, 1991; Kuz'min, 2004; Bakhir et al., 1977), or with particles captured from such motors (Konopka et al., 1984). The results for these particles are shown in detail in Figure 4. Close to these data, according to the level of absorption are the results (Shigapov, 1998) for wavelengths of $0.63 \mu \mathrm{m}$ and $1.15 \mu \mathrm{m}$, obtained in experiments with a pure aluminum oxide melt, being in contact with tungsten, and heated in vacuum. Probably, the high values of $\alpha$, experimentally obtained in this 
work, are a result of either the interaction of the melt with tungsten, or of the influence of the vacuum. There is doubt about the ratio of absorption coefficients at wavelengths of $0.63 \mu \mathrm{m}$ and $1.15 \mu \mathrm{m}$, because as the wavelength decreases at the long wavelength electronic absorption edge (Urbach edge), $\alpha$ must grow. As it is concerns the calculated values of $\alpha$ for wavelengths of $3 \mu \mathrm{m}$ and $6 \mu \mathrm{m}$ in that study, it should be noted that much higher absorption at a wavelength of $3 \mu \mathrm{m}$ compared to $1.15 \mu \mathrm{m}$ can hardly be explained in terms of physics.

The results by Konopka et al. (1984), obtained with purer particles, captured from rocket 1 plume, also have high values of the absorption coefficient. The data on the melt of particles of commercial grade alumina, as was noted by the authors of reference (Konopka et al., 1984), may have certain methodological errors. Most likely they also contained rather a large amount of impurities. The idea of strong effect of impurities was noted in the results presented in (Vorobyev et al., 1999). The melt was prepared by melting of ceramic samples. The obtained values of $\alpha$, though smaller than values characteristic for particles of rocket motors, are nevertheless high.

The character of dependence of the absorption coefficient of molten $\mathrm{Al}_{2} \mathrm{O}_{3}$ on the wavelength, obtained by Konopka et al. (1984), arouse a question. Explanation in physical terms could hardly be a proper one to the abrupt increase in the absorption coefficient at $\lambda>4 \mu \mathrm{m}$. The general character of $\alpha(\lambda)$ must have a minimum between the long wavelength edge of electronic absorption, which is in the visible part of the spectrum, and a short wavelength edge of the band associated with overtones of vibrations of atoms of the bond Al-O. However, the latter edge is unlikely to be at $\lambda>4 \mu \mathrm{m}$. The least value of the absorption coefficient, as it follows from Figures 1, 2 and 4, is expected to be in the region of 3.0-3.5 $\mu \mathrm{m}$.

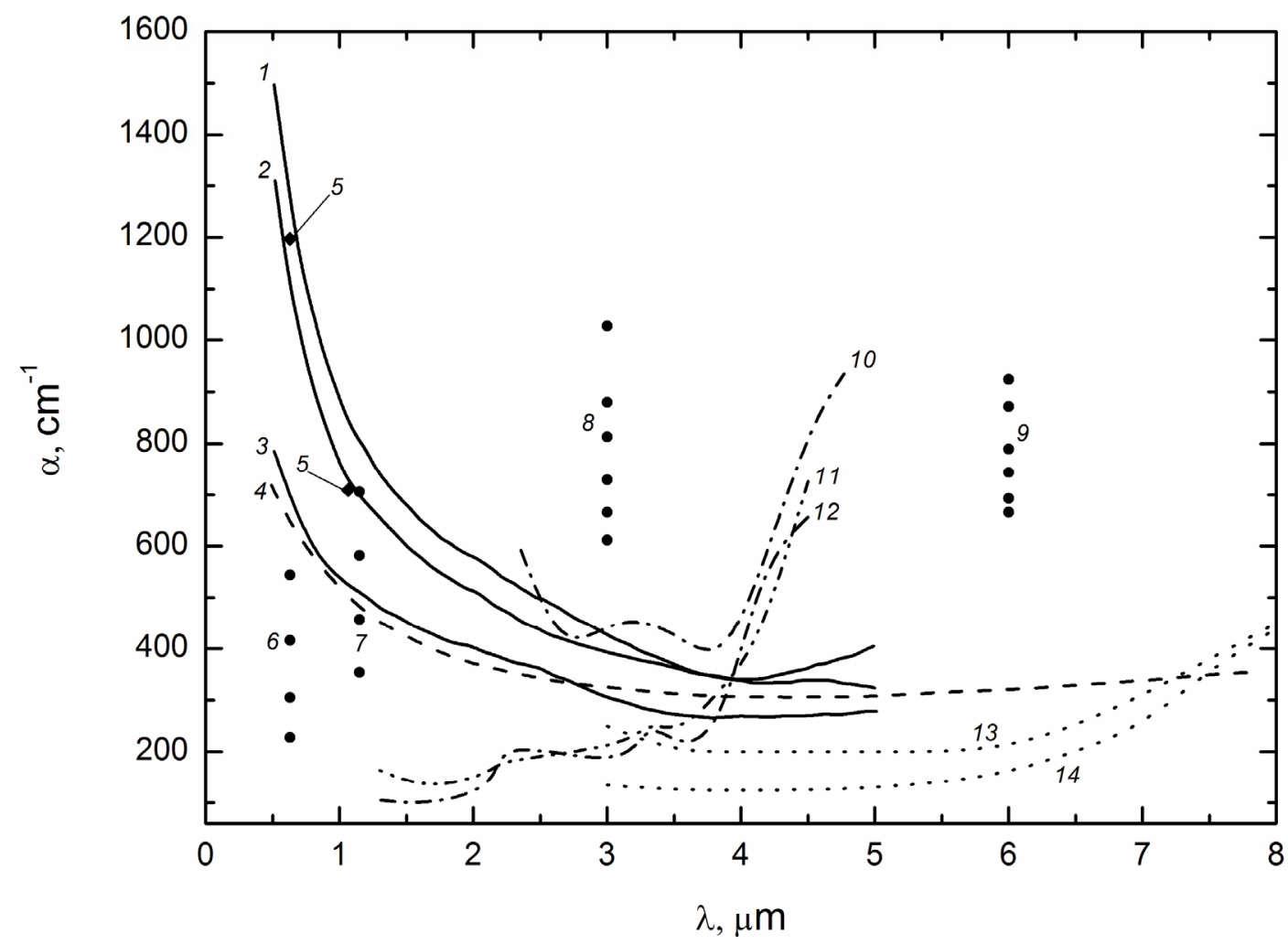

Figure 4. Absorption coefficient of particles from rocket motors and for melts with similar properties

1, 2, 3 - (Kuz'min, 2004) for $3300 \mathrm{~K}, 3000 \mathrm{~K}$ and $2700 \mathrm{~K} ; 4$ - (Bakhir et al., 1977) for $2950 \mathrm{~K} ; 5$ - (Parry \& Brewster, 1991) for $2680 \mathrm{~K} ; 6,7$ - (Shigapov, 1998) for $2400 \mathrm{~K}, 2500 \mathrm{~K}, 2600 \mathrm{~K}, 2700 \mathrm{~K}$; 8, 9 - (Shigapov, 1998 ) for $2400 \mathrm{~K}, 2500 \mathrm{~K}, 2600 \mathrm{~K}, 2700 \mathrm{~K}, 2800 \mathrm{~K}$ and $2900 \mathrm{~K} ; 10$ - (Konopka et al., 1984) for particles of $\mathrm{Al}_{2} \mathrm{O}_{3}$ commercial grade at $2700 \mathrm{~K} ; 11,12$ - (Konopka et al., 1984) for particles of $\mathrm{Al}_{2} \mathrm{O}_{3}$ of rocket motor 1 at $2736 \mathrm{~K}$ and $2959 \mathrm{~K} ; 13,14$ - (Vorobyev et al., 1999) for $2700 \mathrm{~K}$ and $2500 \mathrm{~K}$.

The character of the absorption from the wavelength $\lambda \approx 3 \mu \mathrm{m}$ up to the longest $\lambda=8 \mu \mathrm{m}$, considered by us, for particles containing large amounts of impurities, is largely stipulated by free electrons, which appear due to both these impurities and stacking defects of short-range atomic order, and most likely, as follows from (Krishnan et 
al., 2005), due to the appearance of atoms of free aluminum. Apparently, most correctly the spectral dependence of absorption coefficient is given in the results generalized in (Parry \& Brewster, 1991) (Figure 1). However, the fitting of the empirical parameters was probably made in that study in such a way so as to take into account both the data for particles of rocket motors, and the data for the molten single crystals. This made the authors of reference (Parry \& Brewster, 1991) recommend too low values for particles of rocket motors, lower even than of their own research. But these recommended values lie higher than the data for the molten single crystal and particles obtained from powder of chemically pure aluminum oxide. We included the latter values in the other group and showed them in Figure 5. In this figure we compare that data with the recommended values of (Lingart et al., 1982) for a single crystal in near the melting point (at $2300 \mathrm{~K}$ ). It can be seen that the melt has a much larger absorption coefficient than the crystal in near melting temperature. In Figure 5 the shift is clearly seen of the edge of the electron absorption in the melt towards a longer wavelength region, which speaks of narrowing of the width of the forbidden zone. In addition to a large growth of the absorption coefficient in the region of high transparency, it can be seen the tailing of the minimum in the dependence of $\alpha(\lambda)$, which may be due to contribution of free electrons.

Unfortunately, the temperature range, in which data were received for melts of single-crystal and pure polycrystalline aluminum oxide, is limited from above. In almost all the works the temperature is below $2500 \mathrm{~K}$. Exceptions are only the data in (Sarou-Kanian et al., 2005), where the maximum temperature is $2800 \mathrm{~K}$. Though, firstly, they are obtained only for one wavelength of $3 \mu \mathrm{m}$, and, secondly, in that paper, at $\mathrm{T}>2600 \mathrm{~K}$ there is a decrease of $\alpha$ with temperature, which is connected with a method error, caused, as was said above, by a large optical thickness of the droplet.

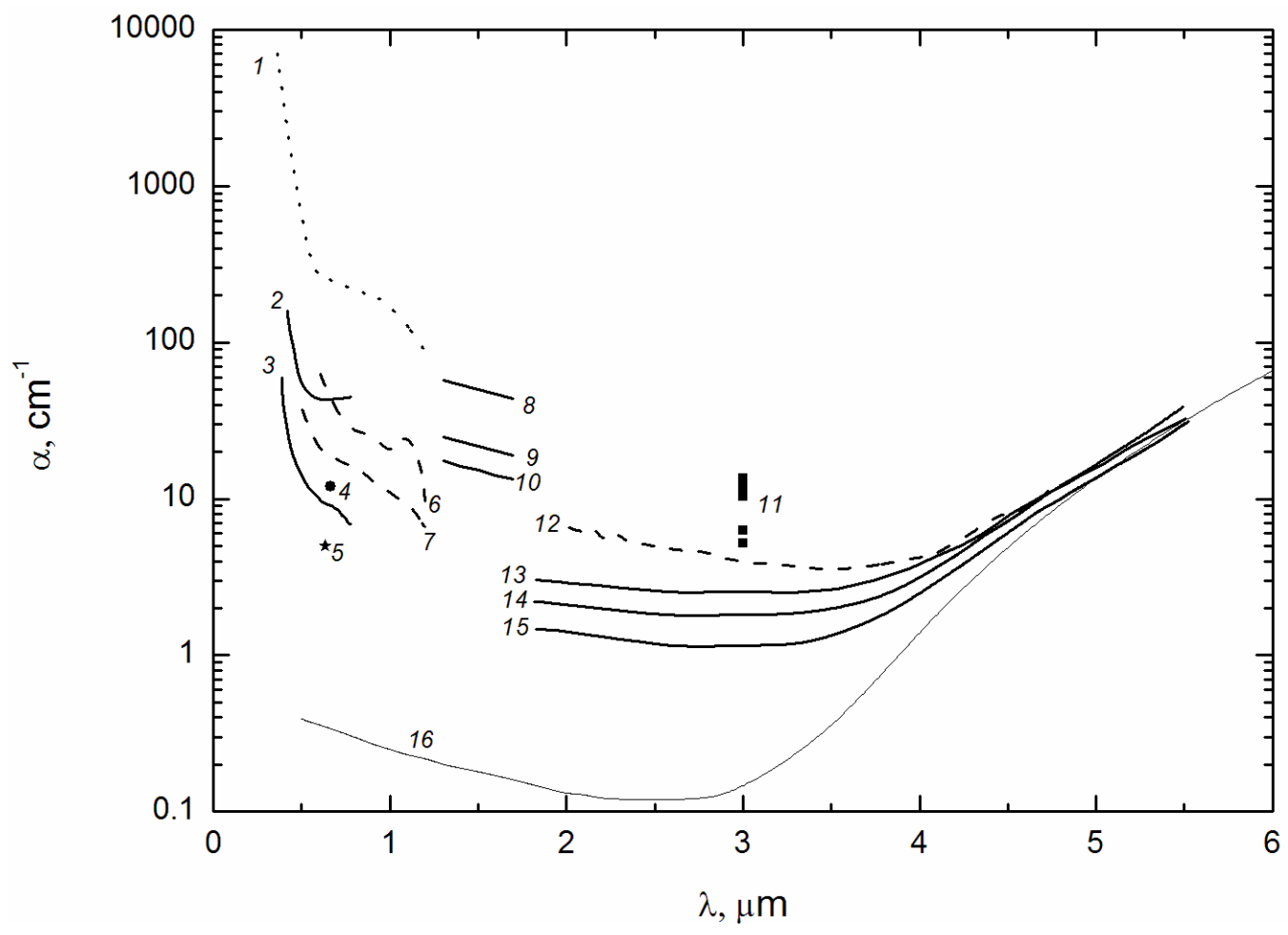

Figure. 5. Absorption coefficient of molten single crystals and some other melts with similar properties

1 - (Mularz \& Yuen, 1972) for $2550 \mathrm{~K} ; 2$, 3 - (Weber, Krishnan et al., 1995) at $2327 \mathrm{~K}$ for oxygen and argon accordingly; 4 - (Abrevaya \& Nordine, 1988) for $2327 \mathrm{~K} ; 5$ - (Nason et al., 1990) for $2473 \mathrm{~K} ; 6$, 7 - (Rubtsov et al., 1984) for $2440 \mathrm{~K}$ and $2330 \mathrm{~K} ; 8,9,10-$ (Carlson, 1965 ) for $2600 \mathrm{~K}, 2400 \mathrm{~K}$ and $2320 \mathrm{~K}$; $11-$ (Sarou-Kanian et al., 2005) for 2327 K, 2400 K, 2500 K, 2600 K, 2700 K, and 2800 K; 12 - (Sarou-Kanian et al., 2005 ) for $2300 \mathrm{~K} ; 13,14,15$ - (Brun et al., 2003) for $2360 \mathrm{~K}, 2340 \mathrm{~K}$ and $2320 \mathrm{~K}$; 16 - recommended data of (Lingart et al., 1982) for single crystal at $2300 \mathrm{~K}$.

Even among these published data the difference of values is too big to generalize them. The factors that 
influence the value of $\alpha$ are the following: the environment around the melt, temperature and time of heating, the purity of the material and others. Therefore, it doesn't seem possible to give general recommendations on the dependence of $\alpha(\lambda, T)$ of a pure $\mathrm{Al}_{2} \mathrm{O}_{3}$ melt. This is typical for the optical properties of materials at high temperatures.

\section{The Refractive Index of Molten Aluminum Oxide}

Along with the absorption coefficient $\alpha$ (the absorption index $\kappa$ ), for calculation of radiation heat transfer it is necessary to know the wavelength and temperature dependences of refractive index $n$ of molten aluminum oxide. It is also needed, in the analysis of the experiments, to calculate optical properties in the measurement of transmission and emission of solid propellant flame. Unfortunately, $n$ is studied worse than $\alpha$. We have succeeded to find only two papers where the experimental data on the refractive index were presented (Figure 6).

In research by Krishnan et al. (1991) the refractive index of pendant drops of laser-heated liquid aluminum oxide was measured by laser ellipsometry at one wavelength of $0.6328 \mu \mathrm{m}$. $n$ was equal to $1.744 \pm 0.016$ at temperatures from $2327 \mathrm{~K}$ to $2600 \mathrm{~K}$. No significant difference was observed in the values measured in oxygen or argon. In reference (Parry \& Brewster, 1991), the refractive index just as the absorption index, was obtained by measurements of direct transmittance and bidirectional transmittance and reflectance using scattered laser light on aluminized solid propellant flames at two wavelengths of 0.6328 and $1.064 \mu \mathrm{m}$ at temperature of $2680 \mathrm{~K}$ The optical properties $n$ and $\kappa$ were calculated by inverse solution of the radiation transfer equation for smoke combustion product. The values of $n$ were equal to 1.65 and 1.64, accordingly. As it may be seen in Figure 6, there is significant difference between experimental data of Krishnan et al. (1991) and Parry and Brewster (1991).

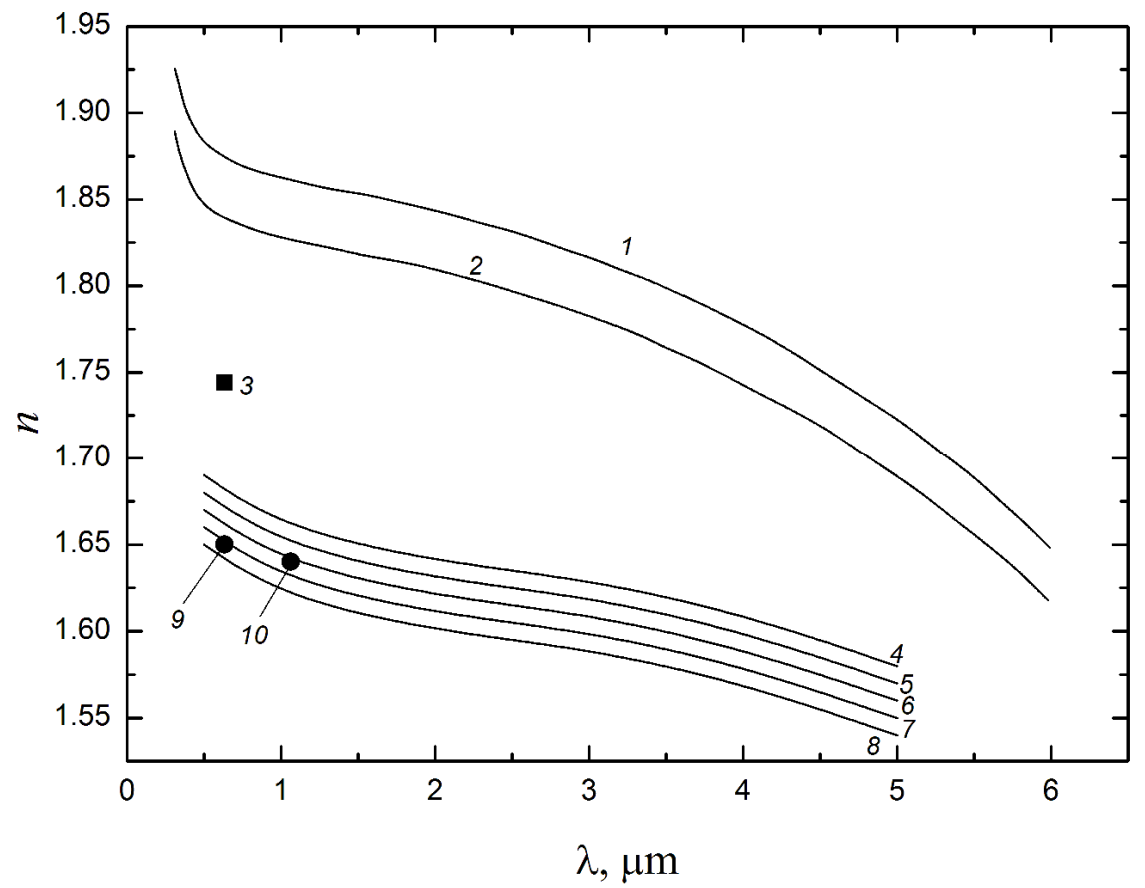

Figure 6. Refractive index of molten aluminum oxide

1, 2 - calculated data (Dombrovsky, 2011) for $3500 \mathrm{~K}$ and $2500 \mathrm{~K}$, accordingly; 3 - experimental data (Krishnan et al., 1991) for temperatures from $2327 \mathrm{~K}$ to $2600 \mathrm{~K} ; 4,5,6,7$ and 8 -calculated data (Parry \& Brewster, 1991) for 2320, 2500, 2680, 2800 and $3000 \mathrm{~K}$, accordingly; 9, 10 - experimental data (Parry \& Brewster, 1991).

There were several attempts to obtain data on the refractive index of liquid aluminum oxide in broad semitransparent spectral range, using simple extrapolation from solid phase data. For example, in reference (Dombrovsky, 2011) it was suggested to use up to $3500 \mathrm{~K}$ in spectral range from 0.3 to $6 \mu \mathrm{m}$ the three-term Sellmeier dispersion equation for synthetic sapphire at room temperature, obtained by Malitson (1962). The linear temperature dependence of the refractive index of liquid aluminum oxide was based in reference 
(Dombrovsky, 2011) on temperature coefficient, taken at $473 \mathrm{~K}$. Density change at heating and melting was not taken into consideration, therefore, very high values of $n$ were obtained.

Another way of obtaining data on the refractive index of liquid aluminum oxide was proposed in reference (Parry \& Brewster, 1991). It was based on the use of Lorentz-Lorenz relation, where the refractive index is related to the density and the molar electronic polarisability. Under the stipulation that the polarisability did not change at melting, the spectral dependence of the refractive index of melt at melting temperature, which was accepted as $2320 \mathrm{~K}$, was obtained. It was done by using of the known data on $n$ of crystal and the values of solid and liquid densities at melting temperature. Along with data at $2320 \mathrm{~K}$, Figure 6 shows data (Parry \& Brewster, 1991) for 2500, 2680, 2800 and $3000 \mathrm{~K}$. These data were extrapolated from the values of $n$ at $2320 \mathrm{~K}$, using the temperature coefficient, which was based on a linear curve fit between the experimental data on $n$ of melt at $2680 \mathrm{~K}$ (at 0.6328 and $1.06 \mu \mathrm{m}$ ) and the values predicted by the Lorentz-Lorenz relation at $2320 \mathrm{~K}$.

As it may be seen in Figure 6, the discrepancy of available data on spectral and temperature dependences of the refractive index of molten aluminum oxide is high, and this question requires further research.

\section{Conclusions}

A joint analysis of the available experimental data on spectral and temperature dependences of the absorption coefficient of molten aluminum oxide has proved that it is hard to make a quantitative comparison of the data of the experiments, where initial materials, ranges of wavelengths, environment and time and temperature conditions are different. Each of these factors influences the value of $\alpha$. Add to this shortage of essential details in the description of the measurement method and measurement conditions, or a poor explanation if any of method errors in some papers.

All the available data on the dependence of $\alpha(\lambda, T)$ of molten aluminum oxide can be divided into two groups which differ according to the level of absorption and maximum temperatures in the studies. Into the first group, with high absorption, there may be included a set of data obtained in experiments with the particles of solid propellant rocket motor exhausts and the particles captured from these motors. The values of the absorption coefficient in this group, even in the maximum transparency region of about 3-4 $\mu \mathrm{m}$ at temperatures of 2500 $3000 \mathrm{~K}$, are $200-400 \mathrm{~cm}^{-1}$.

And the second group of data includes measurement results obtained in experiments with single crystal melts, which are either in contact with crystals, or heated in an aerodynamic levitation. Also, to this group may be added the results obtained using powders of pure $\mathrm{Al}_{2} \mathrm{O}_{3}$. Unfortunately, the temperature level in the results of this group does not exceed $2600 \mathrm{~K}$. In the region of maximum transparency the values of the absorption coefficient do not exceed a few tens of $\mathrm{cm}^{-1}$ in this group.

Discrepancies in the results of different authors in each of these groups are quite big. The explanation lies in the influence of initial material or external conditions, or experimental errors. Therefore, today to give general recommendations for the absorption coefficient of a melt of aluminum oxide is hardly possible, even within each of these groups.

The available results having been considered, it can be said that the common feature of change of $\alpha$ with temperature and wavelength in molten $\mathrm{Al}_{2} \mathrm{O}_{3}$ tends rather to a semiconductor than to an insulator. High absorption on Urbach tail, as temperature increases, takes place not only in visible, but also in short infrared region. High multiphonon absorption takes place at wavelength longer than $4.0 \mu \mathrm{m}$. Between these two regions, absorption is due to free carriers, which are formed by presence of contaminations, impurities, and defects in the local order of atom arrangement.

The abrupt increase of the absorption coefficient of $\mathrm{Al}_{2} \mathrm{O}_{3}$ takes place at melting. The level of this increase is about two orders of magnitude. Analysis of the most novel investigations of atomic structure of molten alumina shows that liquid $\mathrm{Al}_{2} \mathrm{O}_{3}$ has $\gamma$-phase-like atom coordination with many defects. This can be the reason of higher value of the absorption coefficient of the melt in comparison with the single crystal. Rearrangement of atoms and changes in the short-range atomic order also takes place at solidification. However, the kinetics of restructuring of the $\mathrm{Al}_{2} \mathrm{O}_{3}$ melt has not been well enough investigated to date. It is a question of further experimental study. Measurement of optical properties in the opaque infrared spectral range also can give useful information on atom coordination changes. It may be reasonable to measure the band gap for samples of melt, made from a single crystal and from particles, captured in the combustion products of rocket motors.

\section{References}

Abrevaya, H., \& Nordine, P. C. (1988). Evaporation and energy transfer for a partially molten, laser-heated sapphire filament. J. Am. Ceram. Soc., 71, 546-553. http://dx.doi.org/10.1111/j.1151-2916.1988.tb05918.x 
Adams, J. M. (1967). A determination of the emissive properties of a cloud of molten alumina particles. J. Quant. Spectrosc. Radiat. Transfer, 7, 273-277. http://dx.doi.org/10.1016/0022-4073(67)90070-2

Ahuja, R., Osorio-Guillen, J. M., Souza de Almeida, J., Holm, B., Ching, W. Y., \& Johansson, B. J. (2004). Electronic and optical properties of $\gamma-\mathrm{Al}_{2} \mathrm{O}_{3}$ from ab initio theory. J. Phys.: Condens. Matter., 16, 2891-2900. http://dx.doi.org/10.1088/0953-8984/16/16/013

Anfimov, N. A., Karabadjak, G. F., Khmelinin, B. A., Plastinin, Y. A., \& Rodionov, A. V. (1993). Analysis of mechanisms and nature of radiation from aluminum oxide in different phase states in solid rocket exhaust plumes. AIAA Paper 93-2818, In Proceedings of 28-th Thermophysics Conference (pp. 11), Orlando: AIAA.

Ansell, S., Krishnan, S., Weber, J. K. R., Felten, J. J., \& Nordine, P. C. (1997). Structure of liquid aluminum oxide. Phys. Rev. Letters, 78, 464-466. http://dx.doi.org/10.1103/PhysRevLett.78.464

Ault, N. N. (1957). Characteristics of refractory oxide coatings produced by flame-spraying. J. Am. Ceram. Soc., 40(3), 69-74. http://dx.doi.org/10.1111/j.1151-2916.1957.tb12578.x

Bagdasarov, K. S. (2004). Visokotemperaturnaya kristallizatsiya iz rasplava (pp. 21-28). Moskva: Fizmatlit.

Bakhir, L. P., Levashenko, G. I., \& Tamanovich, V. V. (1977). Refinement of imaginary part of complex refractive index of liquid aluminum oxide. Zhurnal Prikladnoy Spektroscopii, 26, 514-520.

Brun, J. F. (2003). Private correspondence, CNRS-CRMHT, E-mail letter of 27.05. 2003

Brun, J. F., De Sousa Meneses, D., \& Echegut, P. (2003). Spectral emissivity of dielectric oxides below and above the melting point: In CD-ROM Proceedings of the Fifteenth Symposium on Thermophysical Properties (pp. 10), Boulder, Colorado: NIST.

Carlson, D. J. (1965). Emittance of condensed oxides in solid propellant combustion products. In Proceedings of 10th International Symposium of Combustion (pp. 1413-1424). Pittsburgh: Combustion Institute.

Coutures, J.-P., Rifflet, J.-Cl., Florian, P., \& Massiot, D. (1994). Etude par analyse thermique et par RMN tres haute temperature de $27 \mathrm{Al}$ de la solidification de $\mathrm{Al} 2 \mathrm{O} 3$ en l'absense de nucleation heterogene: effets de la temperature du liquide et de la pression partielle d'oxygene. Rev. Int. Hautes Temper. Refract., Fr., 29, 123-142.

Dombrovsky, L. A. (2011). Near-infrared properties of droplets of aluminum oxide melt. Thermopedia TM BETA. A to $Z$ Guide to Thermodynamics, Heat \& Mass Transfer, and Fluid Engineering. http://dx.doi.org/10.1615/thermopedia.000149

French, R. H. (1990). Electronic band structure of $\mathrm{Al}_{2} \mathrm{O}_{3}$, with comparison to $\mathrm{AlON}$ and AlN. J. Am. Ceram. Soc., 73, 477-489. http://dx.doi.org/10.1111/j.1151-2916.1990.tb06541.x

Gervais, F. (1991). Aluminum oxide $\left(\mathrm{Al}_{2} \mathrm{O}_{3}\right)$. In E. D. Palik (Ed.), Handbook of Optical Constants of Solids (Vol. II, pp. 761-775). San Diego: Academic Press. http://dx.doi.org/10.1016/B978-012544415-6/50078-9

Gosse, S., Hespel, L., Gossart, P., \& Delfour, A. (2006). Morphological characterization and particle sizing of alumina particles in solid rocket motor. J. Propulsion and Power, 22(1), 127-135. http://dx.doi.org/10.2514/1.13626

Gosse, S., Sarou-Kanian, V., Veron, E., Millot, F., Riffley, J. C., \& Simon, P. (2003). Characterization and morphology of alumina particles in solid propellant subscale rocket motor plumes. AIAA Paper 2003-3649, In Proceedings of 36-th Thermophysics Conference (pp. 8), AIAA, Orlando.

Gryvnak, D. A., \& Burch, D. E. (1965). Optical and infrared properties of $\mathrm{Al}_{2} \mathrm{O}_{3}$ at elevated temperatures. J. Opt. Soc. Amer., 55(6), 625-629. http://dx.doi.org/10.1364/JOSA.55.000625

Gutierres, G., Belonoshko, A. B., Ahuja, R., \& Johansson, B. (2000). Structural properties of liquid $\mathrm{Al}_{2} \mathrm{O}_{3}: \mathrm{A}$ molecular dynamic study. Phys. Rev. E, 61, 2723-2729. http://dx.doi.org/10.1103/PhysRevE.61.2723

Innocenzi, M. E., Swimm, R. T., Bass, M., French, R. H., Villaverde, A. B., \& Kokta, M. R. (1990). Room temperature optical absorption in undoped $\alpha-\mathrm{Al}_{2} \mathrm{O}_{3}$. J. Appl. Phys., 67, 7542-7546. http://dx.doi.org/10.1063/1.345817

Konopka, W. L., Reed, R. A., \& Calia, V. S. (1984). Measurements of infrared optical properties of $\mathrm{Al}_{2} \mathrm{O}_{3}$ rocket particles. In Progress in Astronautics and Aeronautics: Spacecraft Contamination: Sources and Prevention, 91, (pp. 180-196). New York: AIAA.

Krishnan, S., Hennet, L., Jahn, S., Key, T. A., Madden, P. A., Saboungi, M.-L., \& Price, D. L. (2005). Structure of normal and supercooled liquid aluminum oxide. Chem. Mater, 17, 2662-2666. 
http://dx.doi.org/10.1021/cm050254p

Krishnan, S., Weber, J. K. R., Schiffman, R. A., \& Nordine, P. C. (1991). Refractive index of liquid aluminum oxide at 0.6328 $\mu \mathrm{m}$. J. Am. Ceram. Soc., 74, 881-883. http://dx.doi.org/10.1111/j.1151-2916.1991.tb06947.x

Kuz'min, V. A. (2004). Teplpovoye izlucheniye v dvigatelyakh energeticheskikh ustanovok. Kirov: OOO "Firma Poleks, pp. 53-60.

Landron, C., Hennet, L., \& Thiaudiere, D. (2001). Combining measurements of synchrotron radiation and neutrons from liquids at high temperature. Anal. Sci., 17 Supplement, i165-i168.

Landron, C., Hennet, L., Jenkins, T. E., Greaves, G. N., Coutures, J. P., \& Soper, A. K. (2001). Liquid alumina: Detailed atomic coordination determined from neutron diffraction data using empirical potential structure refinement. Phys. Rev. Lett., 86, 4839-4842. http://dx.doi.org/10.1103/PhysRevLett.86.4839

Landron, C., Soper, A. K., Jenkins, T. E., Greaves, G. N., Hennet, L., \& Coutures, J. P. (2001). Measuring neutron scattering structure factor for liquid alumina and analyzing the radial distribution function by empirical potential structural refinement. J. Non-Cryst. Solids, 293-295, 453-457. http://dx.doi.org/10.1016/S0022-3093(01)00839-0

Levi, C. G., Jayaram, V., Valencia, J. J., \& Mehrabian, R. (1988). Phase selection in electrohydrodynamic atomization of alumina. J. Mater. Res., 3, 969-983 http://dx.doi.org/10.1557/JMR.1988.0969

Lingart, Yu. K., Petrov, V. A., \& Tikhonova, N. A. (1982). Optical properties of leucosapphire at high temperatures. I. Semitransparent region. Teplofiz. Vys. Temp., 20, 872-880.

Lynch, D. W. (1985). Interband absorption - mechanisms and interpretation. In E. D. Palik (Ed.) Handbook of Optical Constants of Solids (Vol. I, pp. 189-212). Orlando: Academic Press. http://dx.doi.org/10.1016/B978-012544415-6/50013-3

Malitson, I. H. (1962). Refraction and dispersion of synthetic sapphire. J. Opt. Soc. Amer., 52, 1377-1379. http://dx.doi.org/10.1364/JOSA.52.001377

Mitra, S. S. (1985). Optical properties of nonmetallic solids for photon energies below the fundamental band gap. In E. D. Palik (Ed.). Handbook of Optical Constants of Solids (Vol. I, pp. 213-270). Orlando: Academic Press. http://dx.doi.org/10.1016/B978-012544415-6/50014-5

Mularz, E. J., \& Yuen, M. C. (1972). An experimental investigation of radiative properties of aluminum oxide particles. J. Quant. Spectrosc. Radiat. Transfer, $12, \quad$ 1553-1568. http://dx.doi.org/10.1016/0022-4073(72)90130-6

Nason, D. O., Yen, C. T., \& Tiller, W. A. (1990). Measurement of optical properties of some molten oxides. J. Crystal Growth, 106, 221-226. http://dx.doi.org/10.1016/0022-0248(90)90067-U

Nelson, L. S., Richardson, N. L., Keil, K., \& Skaggs, S. R. (1973). Effects of oxygen and argon atmospheres on pendant drops of aluminum oxide melted with carbon dioxide laser radiation (1973). High Temp. Sci., 5, 138-154.

Nukui, A., Tagai, H., Morikawa, H., \& Iwai, S. I. (1976). Structural conformation and solidification of molten alumina. J. Am. Ceram. Soc., 59, 534-536. http://dx.doi.org/10.1111/j.1151-2916.1976.tb09433.x

Parry, D. L., \& Brewster, M. Q. (1991). Optical constants of $\mathrm{Al}_{2} \mathrm{O}_{3}$ smoke in propellant flames. AIAA J. Thermophysics, 5(2), 142-149. http://dx.doi.org/10.2514/3.241

Petrov, V. A. (2009). Abrupt increase of the absorption coefficient of alumina at melting by laser radiation and its decrease at solidification. Int. J. Thermophys, 30, 1938-1959. http://dx.doi.org/10.1007/s10765-009-0678-z

Petrov, V. A., \& Vorobyev, A. Yu. (2005). Spectral emissivity and radiance temperature plateau of self-supporting $\mathrm{Al}_{2} \mathrm{O}_{3}$ melt at rapid solidification. In L. Vozar, I. Medved, \& L. Kubicar (Eds.), Collection of Manuscripts of the 17th European Conference on Thermophysical Properties (pp. 219-231). Bratislava, Slovakia: Slovak Academy of Sciences.

Petrov, V. A., Titov, V. E., \& Vorobyev, A. Yu. (1999). Numerical simulation of concentrated laser radiation heating of refractory oxides. High Temperatures-High Pressures, 31, 267-274. http://dx.doi.org/10.1068/htrt152

Plastinin, Y. A., Sipatchev, H. Ph., Karabadjak, G. F., Khmelinin, B. A., Khlebnikov, A. G., \& Shiskin, Yu. N. (2000). Influence of alumina particles' phase transition on its radiation in the middle infrared and ultraviolet regions of spectrum. AIAA Paper 2000-0735. In Proceedings of 38-th Thermophysics Conference. (Reno: 
AIAA), $20 \mathrm{pp}$.

Rosenbaum, O., De Sousa Meneses, D., Auger Y., Chermanne, S., \& Echegut, P. (1999). A spectroscopic method to measure the spectral emissivity of semi-transparent materials up to high temperature. Rev. Sci. Instrum., 70, 4020-4025. http://dx.doi.org/10.1063/1.1150028

Rubtsov, N. A., \& Emelyanov, A. A. (1978). Experimental investigation of optical properties of alumina particle flow at high temperature (Preprint No. 25-78). Novosibirsk: Institut teplofiziki SO AN SSSR.

Rubtsov, N. A., Averkov, E. I., \& Emelyanov, A. A. (1988). Svoistva teplovogo izlucheniya materialov v kondensirovannom sostoyanii. Novosibirsk: Institut teplofiziki SO AN SSSR.

Rubtsov, N. A., Emelyanov, A. A., \& Ponomarev, N. N. (1984). Investigation of absorption index of molten aluminum oxide at high temperatures. Teplofiz. Vys. Temp., 22, 294-298.

San Miguel, M. A., Sanz J. F., Fernandes, J., Alvares, L. J., \& Ordiozola, J. A. (1998). Molecular-dynamics simulation of liquid aluminum oxide. Phys. Rev. B, 58, 2369-2371. http://dx.doi.org/10.1103/PhysRevB.58.2369

Sarou-Kanian, V., Rifflet, J. C., \& Millot, F. (2005). IR radiative properties of solid and liquid alumina: Effects of temperature and gaseous environment. Int. J. Thermophys., 26, 1263-1275. http://dx.doi.org/10.1007/s10765-005-6725-5

Shigapov, A. B. (1998). Optical properties of aluminum oxide at high temperatures. Teplofiz. Vys. Temp., 36, $39-43$.

Shigapov, A. B., \& Zikov, V. Yu. (1979). Influence of optical constants on the value of thermal radiation flux. In Teplo-i massoobmen $v$ dvigatelyakh letatel'nykh apparatov (No. 2, pp. 106-111). Kazan': KAI.

Shigapov, A. B., Zikov, V. Yu., Vafin, D. B., \& Klabukov, S. M. (1978). Experimental investigation of optical constants of molten aluminum oxide using laser: In Teplovye processy $i$ svoistva rabochikh tel dvigateley letatel'nykh apparatov (No. 2, pp. 80-86). Kazan': KAI.

Thomas, M. E. (1991). Temperature dependence of the complex index of refraction. In E. D. Palik (Ed.) Handbook of Optical Constants of Solids (Vol. II, pp. 177-201). San Diego: Academic Press. http://dx.doi.org/10.1016/B978-012544415-6/50050-9

Thompson, V. S., \& Whittemore, O. J. (1968). Structural changes on reheating plasma-sprayed alumina. Ceram. Bull., 47, 637-641.

Tropf, W. J., \& Thomas, M. E. (1998). Aluminum oxide $\left(\mathrm{Al}_{2} \mathrm{O}_{3}\right)$ revisited. In E. D. Palik (Ed.), Handbook of Optical Constants of Solids (Vol. III, pp. 653-682).

Vashishta, P., Kalia, R. K., Nakano, A., \& Rino, J. P. (2008). Interaction potential for alumina and molecular dynamics simulations of amorphous and liquid alumina. J. Appl. Phys., 103, 083504, 13. http://dx.doi.org/10.1063/1.2901171

Vorob'ev, A. Yu., Petrov, V. A., Titov, V. E., \& Chernyshev, A. P. (2007). The reflectivity of alumina ceramics under intense surface heating and subsequent free cooling. High Temp., 45, 13-21.

Vorobyev, A. Yu., Petrov, V. A., Titov, V. E., \& Chernyshev, A. P. (1999). Measurement of the absorption coefficient of liquid alumina by thermal wave technique. High Temperatures-High Pressures, 31, 227-234. http://dx.doi.org/10.1068/htec366

Vorobyev, A. Yu., Petrov, V. A., Titov, V. E., \& Fortov, V. E. (2001). Formation of a two-phase zone in the course of rapid solidification of refractory oxides. Physics-Doklady, 46, 651-653. http://dx.doi.org/10.1134/1.1408995

Waseda, Y., Sugiyama, K., \& Toguri, J. M. (1995). Direct determination of the local structure in molten alumina by high temperature X-ray diffraction. Z. Naturforsch, 50a, 770-774.

Weber, J. K. R., Krishnan, S., Anderson, C. D., \& Nordine, P. C. (1995). Spectral absorption coefficient of molten aluminum oxide from 0.385 to $0.780 \mu \mathrm{m}$. J. Am. Ceram. Soc., 78, 583-587. http://dx.doi.org/10.1111/j.1151-2916.1995.tb08218.x

Weber, J. K. R., Nordine, P. C., \& Krishnan, S. (1995). Effects of melt chemistry on the spectral absorption coefficient of molten aluminum oxide. J. Am. Ceram. Soc., 78, 3067-3071. http://dx.doi.org/10.1111/j.1151-2916.1995.tb09084.x 